\title{
Impact of hazard-consistent ground motion duration in structural collapse risk assessment
}

\author{
Reagan Chandramohan*, Jack W. Baker, and Gregory G. Deierlein \\ Department of Civil and Environmental Engineering, Stanford University, Stanford, CA, USA
}

\begin{abstract}
SUMMARY
This study evaluates the effect of considering ground motion duration when selecting hazard-consistent ground motions for structural collapse risk assessment. A procedure to compute source-specific probability distributions of the durations of ground motions anticipated at a site, based on the generalized conditional intensity measure (GCIM) framework, is developed. Targets are computed for three sites in Western USA, located in distinct tectonic settings: Seattle, Eugene, and San Francisco. The effect of considering duration when estimating the collapse risk of a ductile reinforced concrete moment frame building, designed for a site in Seattle, is quantified by conducting multiple stripe analyses using groups of ground motions selected using different procedures. The mean annual frequency of collapse $\left(\lambda_{\text {collapse }}\right)$ in Seattle is found to be underestimated by $29 \%$ when using typical-duration ground motions from the PEER NGA-West 2 database. The effect of duration is even more important in sites like Eugene ( $\lambda_{\text {collapse }}$ underestimated by $\left.59 \%\right)$, where the seismic hazard is dominated by large magnitude interface earthquakes, and less important in sites like San Francisco ( $\lambda_{\text {collapse }}$ underestimated by $7 \%$ ), where the seismic hazard is dominated by crustal earthquakes. Ground motion selection procedures that employ causal parameters like magnitude, distance, and $V s_{30}$ as surrogates for ground motion duration are also evaluated. These procedures are found to produce poor fits to the duration and response spectrum targets due to the limited number of records that satisfy typical constraints imposed on the ranges of the causal parameters. As a consequence, ground motions selected based on causal parameters are found to overestimate $\lambda_{\text {collapse }}$ by $53 \%$. Copyright (c) 2016 John Wiley \& Sons, Ltd.
\end{abstract}

Received 4 August 2015; Revised 31 December 2015; Accepted 5 January 2016

KEY WORDS: duration; hazard-consistent; ground motion selection; Cascadia subduction zone; collapse risk; multiple stripe analysis

\section{INTRODUCTION}

Several questions related to the significance of the duration of strong ground motion often arise when considering the performance of buildings in regions susceptible to large magnitude earthquakes $\left(M_{W} \sim 9.0\right)$. By how much does ground motion duration affect the collapse safety of buildings subjected to large magnitude earthquakes? How might one incorporate ground motion duration into seismic hazard analysis and structural collapse risk assessment? These questions and related issues are examined through illustrated assessments of buildings located at three sites in Western USA with distinct seismic hazards: Seattle (Washington), Eugene (Oregon), and San Francisco (California).

A recent study by the authors [1] demonstrated that the probability of structural collapse is larger under a long duration ground motion than a short duration ground motion with an equivalent response spectrum. This finding corroborates investigations by Raghunandan and Liel [2], but is in contrast to most other previous studies (e.g. [3-6]), which concluded that ground motion duration

*Correspondence to: 439 Panama Mall Room 211, Stanford, CA 94305, USA. Email: reagancestanford. edu 
does not influence peak structural deformations. A number of these studies did not fully quantify the effect of duration due to one or more of the following factors: (i) they used structural models that did not adequately capture deterioration in strength and stiffness, and the destabilizing effect of gravity loads ( $P-\Delta$ effects); (ii) they used predominantly short duration ground motions from shallow crustal earthquakes; (iii) they used duration metrics that were not strongly correlated to structural demands; and (iv) they incompletely accounted for the effect of response spectral shape. Although Chandramohan et al. [1] found ground motion duration to be an important predictor of structural collapse capacity, they did not quantify the duration of ground motion anticipated at any specific site. In this regard, this paper extends previous studies by integrating the seismic hazard characterization of duration with structural collapse risk assessment.

The importance of selecting earthquake ground motions that are representative of the sitespecific seismic hazard, has been highlighted by a number of studies [7-9]. This implies that the characteristics of the selected ground motions should match the characteristics of the ground motions anticipated at the site. A number of documents and standards have been developed to provide guidelines to select representative site-specific ground motions; however, most of them explicitly consider only the response spectra of the selected ground motions. While the response spectrum of a ground motion quantifies its amplitude and frequency content, it is only weakly related to the duration of strong shaking contained in it. Ground motion response spectra have been shown to be well correlated to important structural demand parameters such as peak structural deformations and structural collapse capacity [10-12], thus justifying their widespread use in seismic hazard and risk assessment as a primary ground motion intensity measure. This paper evaluates the impact of matching ground motion duration targets, in addition to response spectrum targets, when selecting site-specific ground motions for structural collapse risk assessment.

NIST GCR 11-917-15 [13] summarizes a number of guidelines for selecting ground motions that are representative of the site seismic hazard. ASCE 7-16 [14] and the PEER Tall Buildings Initiative guidelines [15] require the assessment of structural performance at the risk-targeted maximum considered earthquake $\left(\mathrm{MCE}_{\mathrm{R}}\right)$ ground motion intensity level. They recommend the selection of ground motions, whose response spectra are approximately representative of the site seismic hazard, by scaling them such that the mean of their response spectra lies above the $\mathrm{MCE}_{\mathrm{R}}$ response spectrum at the site. Alternatively, they provide the option of using the conditional mean spectrum [16], which provides a more accurate representation of the site seismic hazard, as a target response spectrum. In addition to response spectra, these standards attempt to implicitly ensure that other characteristics of the selected ground motions, such as duration and pulse-like characteristics, are approximately representative of the site seismic hazard by recommending the selection of ground motions whose causal parameters, such as magnitude, source-to-site distance, and source mechanism, reflect the $\mathrm{MCE}_{\mathrm{R}}$ site hazard.

The actual ground motion selection and modification procedure employed in a given situation depends on the type and objective of the analysis to be conducted. Since ground motions serve as the critical link between seismic hazard analysis and structural demand analysis, obtaining accurate structural response estimates requires the explicit consideration of the joint probability distribution of the response spectral ordinates and durations of the selected ground motions $[17,18]$. This paper outlines a procedure to compute the probability distribution of the durations of ground motions anticipated at a site, conditional on the exceedance of a primary ground motion intensity measure. The procedure is similar to the one used by Iervolino et al. [19] to compute conditional distributions of the Cosenza and Manfredi index, $I_{D}$ [20], but extends upon it in a number of ways, as described below. The proposed procedure recommends computing different conditional distributions of ground motion duration for each type of seismic source that contributes to the site seismic hazard, e.g. interface, in-slab, and crustal earthquakes, at each considered hazard level. The computation procedure is based on the generalized conditional intensity measure (GCIM) framework [21]. The conditional distributions of duration are computed using seismic hazard deaggregation [22] results, a ground motion prediction equation for duration (e.g. [23-25]), and a model for the correlation coefficient between the total residuals, or $\varepsilon$-values, of duration and the chosen primary ground motion intensity measure (e.g. [26]). These source-specific conditional 
distributions of duration are then used in conjunction with source-specific conditional spectra (CS) $[16,27,28]$ as targets to select appropriate proportions of hazard-consistent ground motions corresponding to each type of seismic source.

The potential for sites in Western USA to experience long duration ground motions stems mainly from large magnitude interface earthquakes in the Cascadia subduction zone. Source-specific target distributions of duration and response spectra are computed at three representative sites in Western USA-Seattle (Washington), Eugene (Oregon), and San Francisco (California)—with different levels of contribution to their seismic hazard from interface, in-slab, and crustal earthquakes. The collapse risk of an eight-story reinforced concrete moment frame building located in Seattle is estimated by conducting multiple stripe analysis using three groups of ground motion sets: (i) CS and duration group selected to match response spectrum and duration targets; (ii) CS only control group selected to match response spectrum targets only; and (iii) CS and causal parameters group selected to match response spectrum targets and deaggregated ranges of earthquake causal parameters like magnitude and source-to-site distance. The multiple stripe analysis technique [29] is chosen to conduct the analyses since it allows the use of different sets of hazard-consistent ground motions at different intensity levels. Finally, the bootstrap method [30] is proposed to quantify the uncertainty in the collapse risk estimates. It is used here to estimate the sampling distribution and standard error of the difference between the mean annual frequency of collapse, $\lambda_{\text {collapse }}$, estimated using two alternative groups of ground motion sets. The difference between the $\lambda_{\text {collapse }}$ values estimated using the CS and duration and CS only groups is used to quantify the significance of considering ground motion duration when selecting ground motions for collapse risk estimation. The difference between the $\lambda_{\text {collapse }}$ values estimated using the CS and causal parameters and CS and duration groups is used to assess the suitability of ground motion selection procedures that employ earthquake causal parameters to implicitly capture the effect of ground motion duration.

\section{COMPUTATION OF SOURCE-SPECIFIC TARGET DISTRIBUTIONS OF DURATION}

The proposed procedure to compute the source-specific target distribution of duration at a specific hazard level is based on the GCIM framework [21]. The GCIM framework is a generalization of the conditional spectrum $[16,27,28]$ that allows consideration of a general set of ground motion intensity measures, beyond only response spectral ordinates. The procedure begins with the choice of $(i)$ an amplitude-based conditioning ground motion intensity measure, which is quantified by probabilistic seismic hazard analysis (PSHA) [31,32], and (ii) a metric to quantify ground motion duration. In this study, the $5 \%$ damped pseudo spectral acceleration, $S_{a}\left(T^{*}\right)$, is used as the conditioning intensity measure, which is consistent with current structural design practice in the USA. The conditioning period, $T^{*}$, is a period of vibration that is representative of the dynamic behavior of the structure under consideration, usually chosen as the fundamental elastic modal period of the structure. Ground motion duration is quantified by significant duration [33], Ds, since it was previously identified to be a good predictor of structural collapse capacity [1], and it can be readily estimated using previously published prediction equations. The significant duration of a ground motion is defined as the time

interval over which a specific percentage range of the integral $\int_{0}^{t_{\max }} a^{2}(t) d t$ is accumulated, where $a(t)$ represents the ground acceleration at time $t$, and $t_{\max }$ represents the length of the accelerogram. 5-75\% significant duration, $D s_{5-75}$, is used in this paper, and its computation is illustrated in Fig. 1. Although $S_{a}\left(T^{*}\right)$ and $D s_{5-75}$ are used here, the described procedure is general and can be used with any combination of conditioning intensity measure and duration metric.

Note that it is infeasible to use traditional PSHA to obtain a hazard curve that describes the mean annual frequency of exceedance of significant duration, as is typically done for amplitude-based intensity measures like $S_{a}$, because significant duration increases with distance from the seismic source. Therefore, extremely long duration ground motions originating from a number of distant sources can contribute significantly to the seismic duration hazard at a site, although they have low spectral acceleration values and are not of engineering consequence. This is one motivation behind 


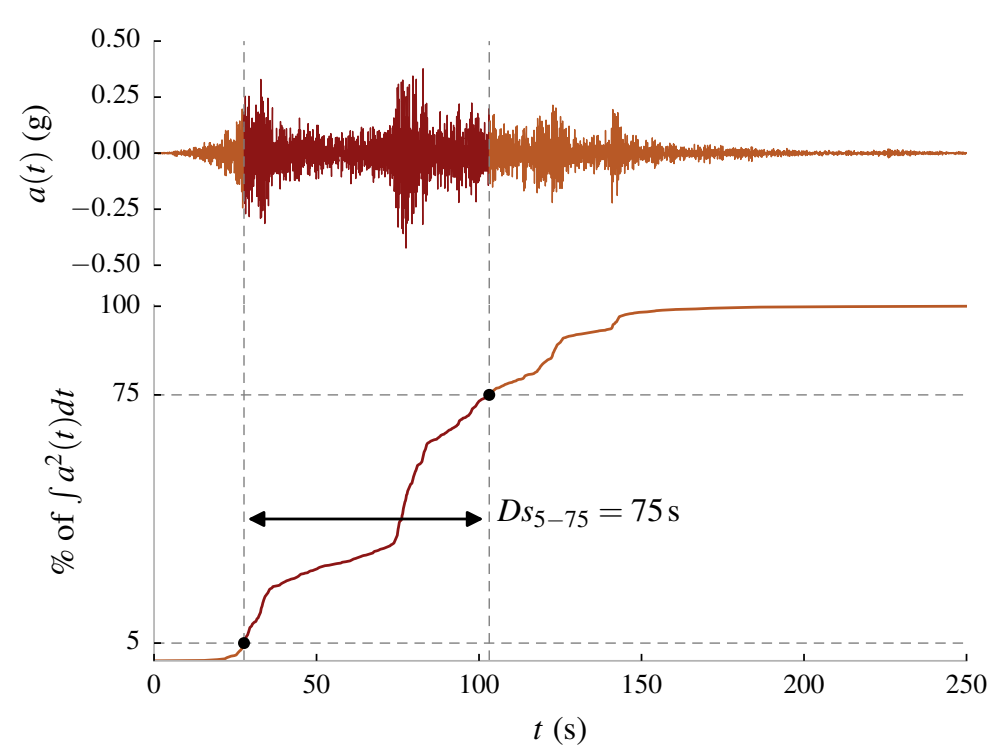

Figure 1. (Top) East-West component of the accelerogram recorded from the 2011 Tohoku (Japan) earthquake at the Sakunami station (station code: MYG014), and (Bottom) the normalized, cumulative integral of $a^{2}(t)$ illustrating the computation of 5-75\% significant duration of the accelerogram.

computing target distributions of duration, conditional on the exceedance of a primary, amplitudebased ground motion intensity measure.

\subsection{Target computation procedure}

To compute the source-specific conditional distribution of duration, the $S_{a}\left(T^{*}\right)$ value corresponding to the chosen hazard level is first obtained from the standard hazard curve. Seismic hazard deaggregation is then used to find the earthquake scenarios that are most likely to cause the exceedance of that $S_{a}\left(T^{*}\right)$ value at the site, defined by the following parameters: $(i)$ source type, $S T_{i}$ (e.g. interface, in-slab, or crustal), (ii) magnitude, $M_{i}$, (iii) source-to-site distance, $R_{i},($ iv) other causal parameters, $\Theta_{i}$ (e.g. $V s_{30}$ : the average shear wave velocity of the top $30 \mathrm{~m}$ of the soil profile, faulting mechanism, and basin depth), (v) total residual or $\varepsilon$-value for $S_{a}\left(T^{*}\right), \varepsilon_{i}$, and (vi) deaggregation weight, $p_{i}$, where the subscript $i$ denotes the $i^{t h}$ contributing earthquake scenario. A prediction equation for significant duration (e.g. [23-25]) is then used to compute the mean, $\mu$, and standard deviation, $\sigma$, of the natural logarithm of the significant duration of the ground motions anticipated at the site from each contributing earthquake scenario, as functions of its $M, R$, and $\Theta$ :

$$
\begin{aligned}
\mu_{\ln D s(i)} & =f\left(M_{i}, R_{i}, \boldsymbol{\Theta}_{i}\right) \\
\sigma_{\ln D s(i)} & =g\left(M_{i}, R_{i}, \mathbf{\Theta}_{i}\right)
\end{aligned}
$$

where $f()$ and $g()$ denote functions defined by the prediction equation. The logarithm of significant duration is used since many prediction equations have found it to be lognormally distributed for a given earthquake scenario [23-25]. The conditional distribution of significant duration for each contributing earthquake scenario is then computed using Eqs. (2a) and (2b), which require a model for the correlation coefficient, $\rho\left(T^{*}\right)$, between the $\varepsilon$-values from the predictions of the logarithms of $S_{a}\left(T^{*}\right)$ and $D s$ (e.g. [26]).

$$
\begin{aligned}
& \mu_{\ln D s(i) \mid \ln S_{a}\left(T^{*}\right)}=\mu_{\ln D s(i)}+\rho\left(T^{*}\right) \varepsilon_{i} \sigma_{\ln D s(i)} \\
& \sigma_{\ln D s(i) \mid \ln S_{a}\left(T^{*}\right)}=\sigma_{\ln D s(i)} \sqrt{1-\rho\left(T^{*}\right)^{2}}
\end{aligned}
$$

The relative contribution to the total site seismic hazard from each type of seismic source is computed by summing the deaggregation weights corresponding to all contributing earthquake 
scenarios from that type of seismic source, using Eq. (3),

$$
\bar{p}_{(s t)}=\sum_{S T_{i}=s t} p_{i}
$$

where $S T$ is a random variable and $s t$ represents a specific source type, e.g. interface, in-slab, or crustal. Source-specific conditional distributions of significant duration are then computed for each seismic source type, st, as a weighted average of the conditional distributions of significant duration for all contributing earthquake scenarios from that type of seismic source, using Eqs. (4a) and (4b).

$\begin{aligned} \mu_{\ln D s(s t) \mid \ln S_{a}\left(T^{*}\right)} & =\sum_{S T_{i}=s t} \frac{p_{i}}{\bar{p}_{(s t)}}\left[\mu_{\left.\ln D s(i) \mid \ln S_{a}\left(T^{*}\right)\right]}\right. \\ \sigma_{\ln D s(s t) \mid \ln S_{a}\left(T^{*}\right)} & =\sqrt{\sum_{S T_{i}=s t} \frac{p_{i}}{\bar{p}_{(s t)}}\left[\sigma_{\ln D s(i) \mid \ln S_{a}\left(T^{*}\right)}^{2}+\left(\mu_{\ln D s(i) \mid \ln S_{a}\left(T^{*}\right)}-\mu_{\left.\left.\ln D s(s t) \mid \ln S_{a}\left(T^{*}\right)\right)^{2}\right]}\right.\right.}\end{aligned}$

These equations are similar to the ones proposed by Lin et al. [34] to compute conditional spectra, except in this case, separate target distributions are computed for each type of seismic source. The motivation for doing this will be illustrated in Section 3.3. Note that although the inputs to Eqs. (4a) and (4b) are the means and standard deviations of lognormal distributions, the aggregate sourcespecific conditional distributions are not necessarily lognormal. They are, however, approximated here as lognormal distributions for practical reasons. Source-specific conditional spectra can be similarly computed using appropriate prediction equations and models for the correlation coefficient between response spectral ordinates.

To select a set of hazard-consistent ground motions at the chosen hazard level, the fraction of ground motions selected to match the target $D s_{5-75}$ distribution and conditional spectrum corresponding to each type of seismic source should be equal to the $\bar{p}_{(s t)}$ value computed for that type of seismic source using Eq. (3). Several algorithms have been proposed to select ground motions whose characteristics match a given joint distribution of ground motion intensity measures $[17,35]$.

\subsection{Prediction models for significant duration}

Three prediction equations for significant duration are considered in this study: Abrahamson and Silva [23], Kempton and Stewart [24], and Bommer et al. [25]. These prediction equations were all developed for crustal earthquakes using the PEER NGA-West database [36], with Bommer et al. having the largest maximum usable magnitude of 7.9. The authors are currently unaware of any significant duration prediction equations for large magnitude interface earthquakes and deep in-slab earthquakes. Nevertheless, since large magnitude interface earthquakes in the Cascadia subduction zone are the focus of this study $\left(8.6 \leq M_{W} \leq 9.3\right.$ as per [37]), the ability of the three models to predict durations of ground motions produced by large magnitude interface earthquakes, above their maximum usable magnitude limits, was investigated.

The variation, with magnitude, of the median $D s_{5-75}$ predicted by the three models, at a rock site and source-to-site distances of $10 \mathrm{~km}$ and $80 \mathrm{~km}$, are plotted in Fig. 2. Predictions extrapolated beyond the maximum usable magnitude of each model are plotted using a dashed line. $D s_{5-75}$ is seen to increase with both earthquake magnitude and source-to-site distance but is typically more sensitive to changes in magnitude than distance. The predictions of the three models are found to agree well until a magnitude of about 7.5, above which they diverge. Notably, at magnitudes above 7.9, Bommer et al. is found to predict longer duration ground motions at shorter distances, indicated by the crossing of the Distance $=10 \mathrm{~km}$ and Distance $=80 \mathrm{~km}$ curves, which is contrary to expectations based on wave propagation physics, thus making it unsuitable for use with the large magnitude earthquakes considered in this study. The predictions of the Abrahamson and Silva, and Kempton and Stewart models were found to be consistent with the durations of ground motions produced by recent large magnitude interface earthquakes from a qualitative comparison, thus 


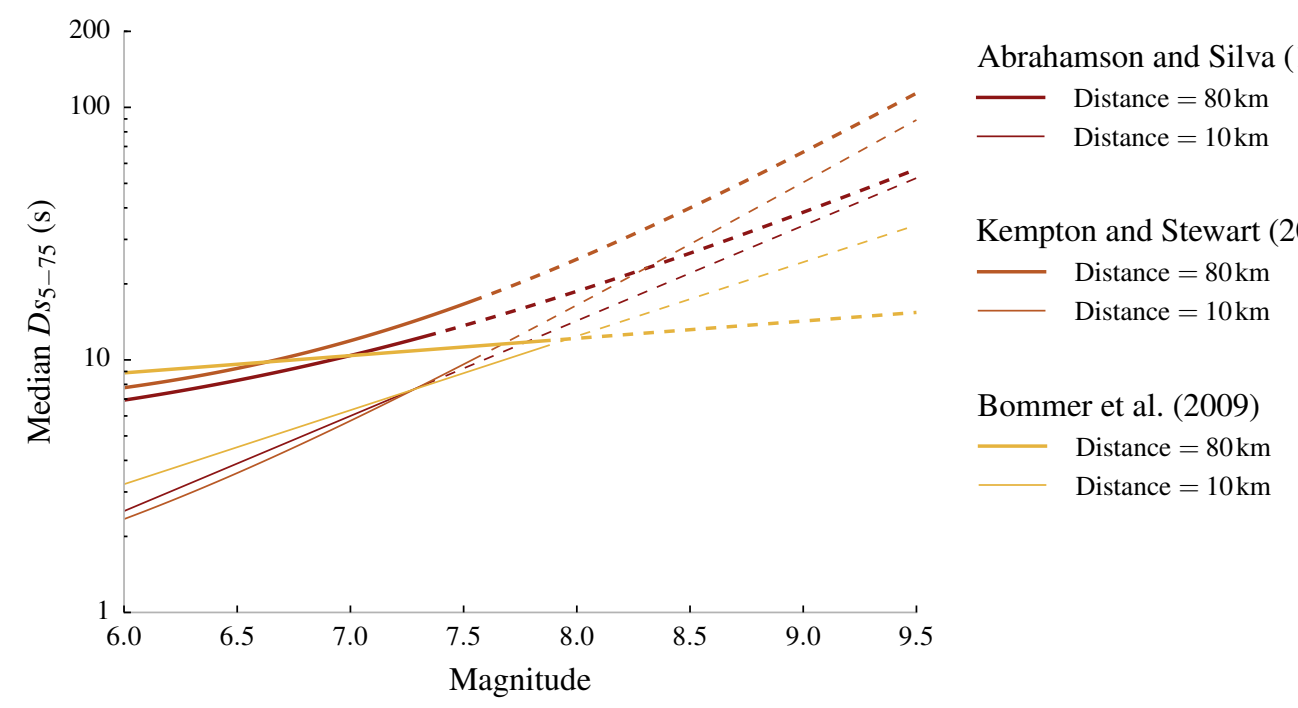

Figure 2. Comparison of the three prediction equations for significant duration. Durations predicted by extrapolating the models above their range of calibrated magnitudes are plotted using a dashed line.

supporting their use in this study, especially given the absence of any alternatives. Among the two, Kempton and Stewart consistently predicts longer duration ground motions than Abrahamson and Silva. The Abrahamson and Silva equation is used in the calculations presented in Section 3, and the collapse risk assessments in Section 4, to conservatively demonstrate the effect of ground motion duration; the effect would be even larger if the Kempton and Stewart model were used instead.

The only available model for the correlation coefficient between the $\varepsilon$-values of $S_{a}\left(T^{*}\right)$ and $D s_{5-75}$ was also developed for crustal earthquakes using the PEER NGA-West database [26]. The model predicts small negative correlation coefficients for periods shorter than $2.1 \mathrm{~s}$, and small positive correlation coefficients for periods longer than $2.1 \mathrm{~s}$. While the properties of these models are believed to be reasonable for the calculations presented below, there is need for additional studies to verify the application of these models to interface and in-slab earthquakes.

\section{ANALYSIS OF SOURCE-SPECIFIC TARGETS COMPUTED FOR WESTERN USA}

The procedure outlined in Section 2 was used to compute source-specific target distributions of $D s_{5-75}$, conditional on the $2 \%$ in 50 year exceedance probability of $S_{a}(1 \mathrm{~s})$, for Western USA. Seismic hazard deaggregation results were obtained from the USGS [38,39]. The duration prediction models discussed above were used in the computations, assuming a rock site with $V s_{30}=$ $760 \mathrm{~m} / \mathrm{s}$. Maps of the percentage contribution to the seismic hazard from interface earthquakes, and the conditional median target $D s_{5-75}$ of ground motions produced by interface earthquakes in the Cascadia subduction zone, for locations that have non-zero contributions to their seismic hazard from interface earthquakes, are shown in Figs. 3a and $3 \mathrm{~b}$ respectively. A map of the $S_{a}(1 \mathrm{~s})$ values that are exceeded with a probability of $2 \%$ in 50 years is shown in Fig. 3c.

In Fig. 3b, the conditional median target $D s_{5-75}$ of ground motions produced by interface earthquakes is seen to increase from around $30 \mathrm{~s}$ near the Pacific coast to around $45 \mathrm{~s}$ at distances about $600 \mathrm{~km}$ inland, due to the increase in predicted $D s_{5-75}$ with distance from the Cascadia subduction zone. As seen in Fig. 3a, this increase in target duration is, however, accompanied by a corresponding decrease in the percentage contribution to the total seismic hazard from interface earthquakes, from almost $100 \%$ near the Pacific coast to $0 \%$ at distances around $600 \mathrm{~km}$ inland. Localized drops in the percentage contribution from interface earthquakes are also observed around seismically active crustal faults near Seattle, Southern Oregon, and Northern California. The $S_{a}(1 \mathrm{~s})$ value corresponding to a $2 \%$ probability of exceedance in 50 years decreases from 
values greater than $0.6 \mathrm{~g}$ near the Pacific coast to below $0.2 \mathrm{~g}$ at distances around $300 \mathrm{~km}$ inland. Therefore, although longer duration ground motions are expected at larger distances from the Cascadia subduction zone, the relative contribution of these long duration ground motions produced by interface earthquakes to the total seismic hazard, as well as the expected intensity of these ground motions, decreases with distance. As a result, ground motion duration is an important consideration for structural performance assessment only at sites located near the Cascadia subduction zone. The exact magnitude of the importance, however, depends on parameters like the conditioning period and the intensity level, as discussed in Section 3.2.

\subsection{Targets at three representative sites}

Three sites located in Seattle, Eugene, and San Francisco were chosen to illustrate how proximity to different types of seismic sources can influence the site seismic hazard. The sites are located in different tectonic settings with varying levels of contribution to their seismic hazard from different types of seismic sources, as shown in Fig. 4. San Francisco's seismic hazard comes almost entirely from crustal faults, including the San Andreas, Hayward, and San Gregorio faults. Eugene, on the other hand, is adjacent to the Cascadia subduction zone and distant from seismically active crustal faults; hence the subduction zone is the dominant contributor to its seismic hazard. Seattle's seismic hazard is affected by both the Cascadia subduction zone and the Seattle fault zone, which is a network of crustal faults under the city.

The Cascadia subduction zone is a source of both interface and in-slab earthquakes. The large magnitude interface earthquakes are caused by relative motion between the subducting Juan de Fuca plate, and the over-riding North American plate. The 2014 USGS national seismic hazard maps [37] consider future interface earthquakes of magnitude as large as 9.3 in the Cascadia subduction zone. The 1700 Cascadia earthquake was an interface earthquake of estimated magnitude 9.0. In-slab earthquakes are deep earthquakes caused by ruptures within the subducting Juan de Fuca plate as it sinks into the mantle, at depths of $35 \mathrm{~km}$ to $70 \mathrm{~km}$ [37]. Although in-slab earthquakes are of smaller magnitude than interface earthquakes, they are much more frequent. The 2001 Nisqually earthquake was an in-slab earthquake of magnitude 6.8 .

Seismic hazard deaggregation plots, conditional on the $2 \%$ in 50 year exceedance probability of $S_{a}(1 \mathrm{~s})$, for all three sites, are shown in Fig. 5. The contributions from each type of seismic source are easily distinguishable since they have distinct magnitude and source-to-site distance ranges. The computed source-specific conditional median target $D s_{5-75}$ values, and the corresponding percentage contributions to the total seismic hazard from each type of seismic source, conditional on the $2 \%$ in 50 year exceedance probability of $S_{a}(1 \mathrm{~s})$, are summarized in Table I. The sourcespecific conditional distributions of $D s_{5-75}$, and the source-specific conditional spectra, which are computed in an analogous manner, are plotted in Fig. 6. Note that the conditional standard deviations of the conditional spectra are omitted for readability, and the percentage contributions of each type of source to the total seismic hazard are noted in the legends. The BC Hydro [40] prediction equation was used to compute the conditional spectra for the interface and in-slab earthquakes, and the Campbell and Bozorgnia [41] prediction equation was used for the crustal earthquakes. The correlation coefficients between the $\varepsilon$-values of response spectral ordinates at different periods from [42] were used for crustal and in-slab earthquakes, and those from [43] were used for interface earthquakes. The difference in the expected frequency content of ground motions produced by earthquakes from different types of seismic sources, is evident from Fig. 6. As seen from the plotted conditional mean spectra, ground motions from interface earthquakes are expected to have less highfrequency content, whereas those from in-slab earthquakes are expected to have less low-frequency content, when compared to crustal earthquakes.

\subsection{Sensitivity of targets to seismic hazard level and conditioning period}

The duration targets computed above were conditional on the $2 \%$ in 50 year exceedance probability of $S_{a}(1 \mathrm{~s})$. Figure 7 plots the duration targets in Seattle corresponding to interface earthquakes, for three conditioning periods, and for $S_{a}\left(T^{*}\right)$ values with varying return periods. Figure 7a shows that for shorter conditioning periods, intense ground motions (corresponding to longer return periods) 


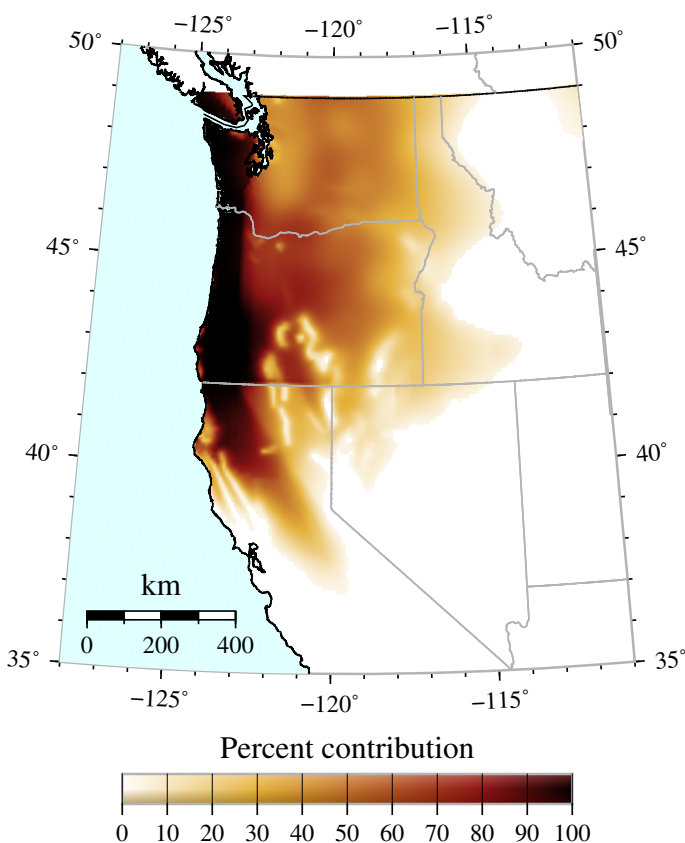

(a)

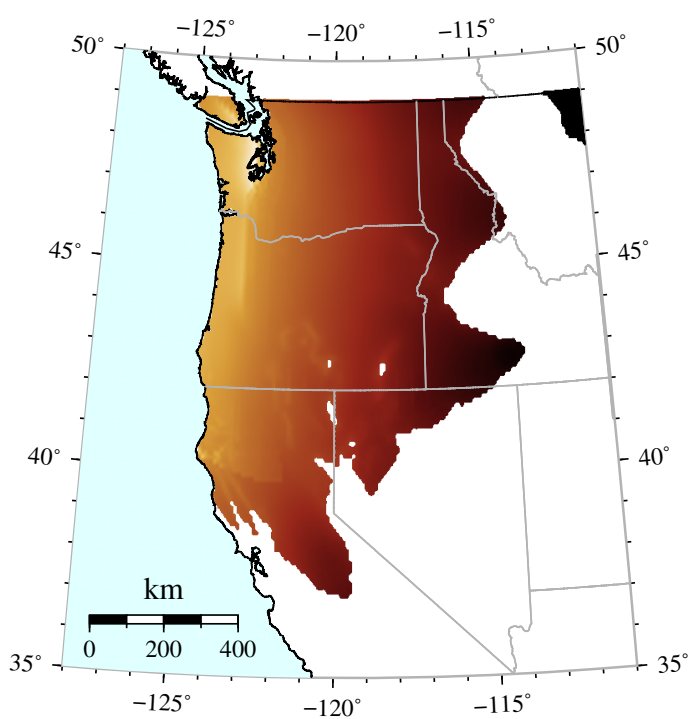

$\operatorname{Ds}_{5-75}(\mathrm{~s})$

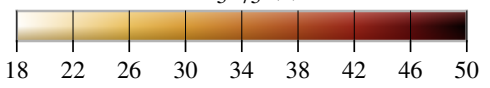

(b)

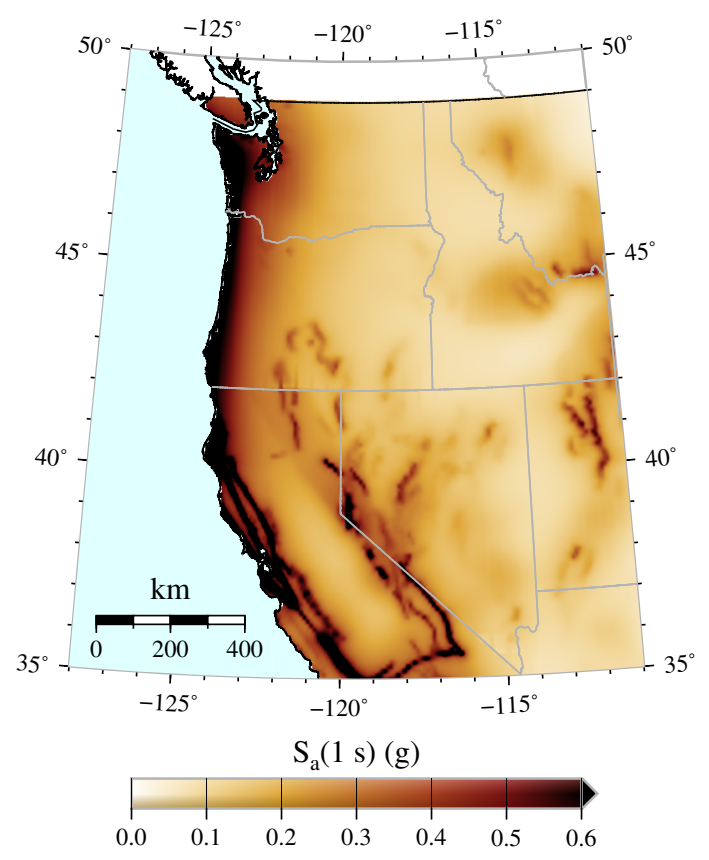

(c)

Figure 3. (a) Percentage contribution to the total seismic hazard from interface earthquakes, and (b) conditional median target $D s_{5-75}$ of ground motions produced by interface earthquakes (only plotted for sites with non-zero contributions to their seismic hazard from interface earthquakes), conditional on the exceedance of the $S_{a}(1 \mathrm{~s})$ values shown in (c), which are exceeded with a probability of $2 \%$ in 50 years.

are likely to have shorter durations. This trend is explained by the larger $\varepsilon$-values associated with rarer ground motions, and the negative correlation between the $\varepsilon$-values of $D s_{5-75}$ and $S_{a}\left(T^{*}\right)$ for shorter conditioning periods [26], used in Eq. (2a). For longer conditioning periods, [26] predicts positive correlation coefficients, resulting in rare, intense ground motions being associated with 


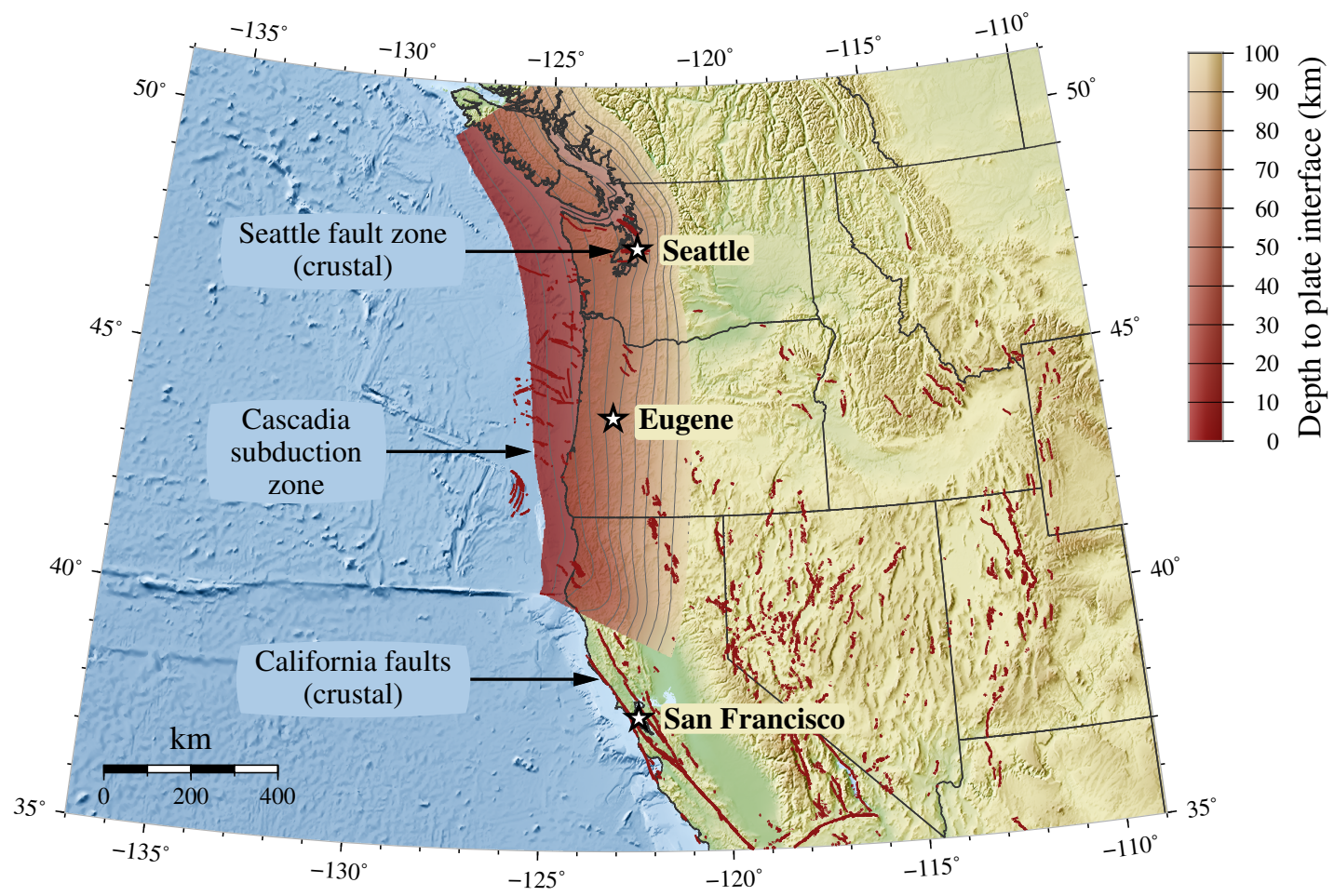

Figure 4. Sites chosen for sample calculations of target distributions of duration, and the seismic sources that significantly contribute to their seismic hazard.

Table I. Source-specific conditional median target $D s_{5-75}$ values, and the corresponding percentage contributions to the total seismic hazard from each type of seismic source (indicated in parentheses), conditional on the $2 \%$ in 50 year exceedance probability of $S_{a}(1 \mathrm{~s})$, for all three considered sites. Conditional median target $D s_{5-75}$ values are not indicated for source types that contribute less than $1 \%$ to the site seismic hazard.

\begin{tabular}{cccc}
\hline Site & Interface earthquakes & In-slab earthquakes & Crustal earthauakes \\
\hline Seattle & $32 \mathrm{~s}(35 \%)$ & $7 \mathrm{~s}(24 \%)$ & $5 \mathrm{~s}(41 \%)$ \\
Eugene & $30 \mathrm{~s}(93 \%)$ & $8 \mathrm{~s}(7 \%)$ & - \\
San Francisco & - & - & $9 \mathrm{~s}(100 \%)$ \\
\hline
\end{tabular}

longer durations. The unconditional median target durations were found to stay relatively constant over different hazard levels, and thus, do not contribute significantly to the observed trends.

Figure $7 \mathrm{~b}$ shows that the relative contribution of interface earthquakes to the total seismic hazard is higher at longer return periods, on average. A consequence of this is that when analyzing a structure in Seattle, a larger proportion of long duration ground motions, characteristic of interface earthquakes, would need to be used at higher ground motion intensity levels. It is also observed from Fig. $7 \mathrm{~b}$ that interface earthquakes contribute more to the seismic hazard at longer conditioning periods. This is explained by the fact that the prediction equations for interface earthquakes used in the 2008 national seismic hazard model [39] predict ground motions that are rich in low-frequency content. It, therefore, follows that large $S_{a}\left(T^{*}\right)$ values at long periods are more likely to be caused by interface earthquakes. This pattern is, however, not reflected in the conditional mean spectra for Seattle plotted in Fig. 6a, where the conditional mean spectrum corresponding to crustal earthquakes has about the same low-frequency content $\left(S_{a}(T>1 \mathrm{~s})\right)$ as the one corresponding to interface earthquakes. This discrepancy is a consequence of using the BC Hydro [40] prediction equation to compute the conditional mean spectra in Fig. 6a, although it is not used in the deaggregation computations in [39] used to plot Fig. 7b. The BC Hydro [40] model predicts a rapid decay in the low-frequency content of ground motions produced by interface earthquakes with distance, thus 


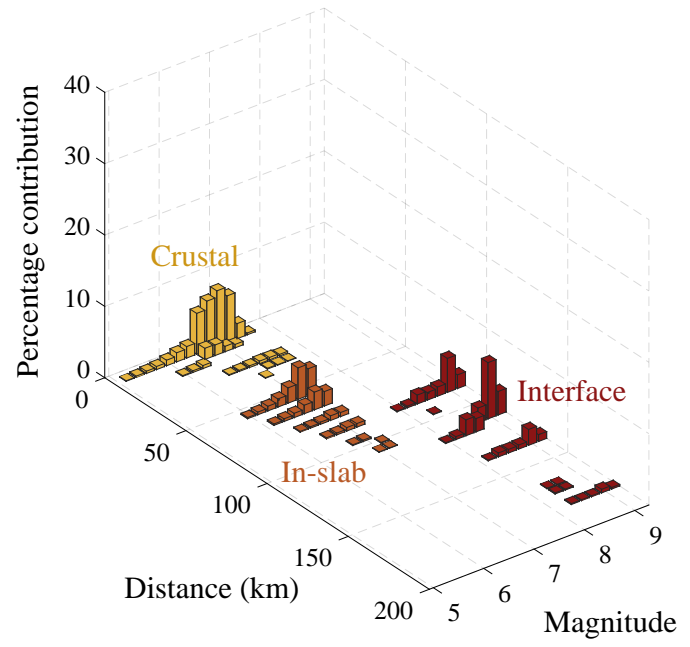

(a) Seattle

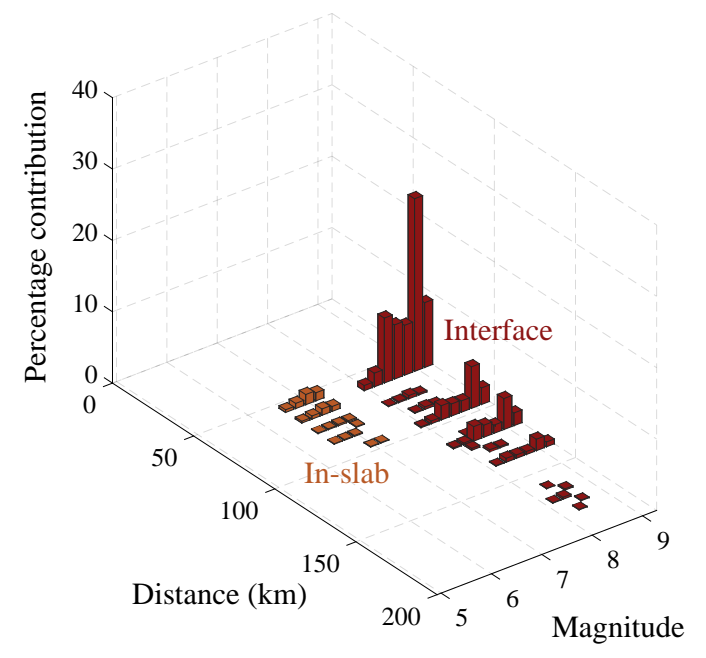

(b) Eugene

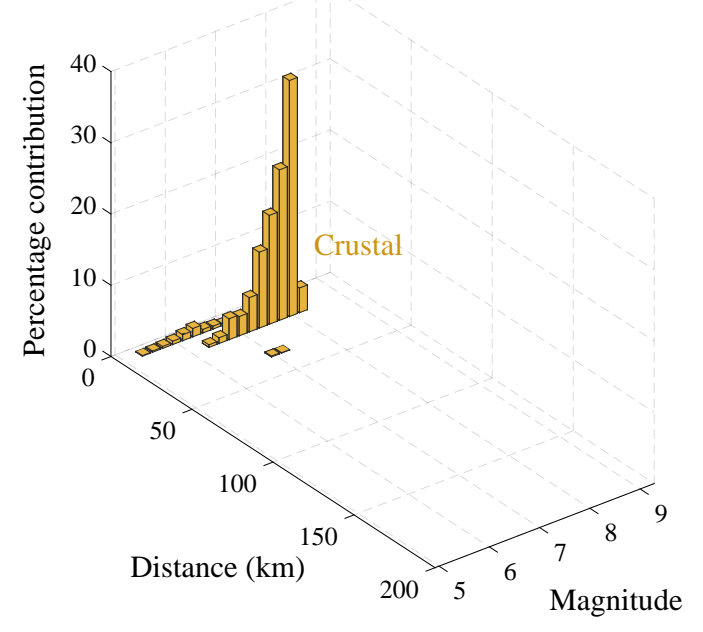

(c) San Francisco

Figure 5. Seismic hazard deaggregation plots for all three considered sites, conditional on the $2 \%$ in 50 year exceedance probability of $S_{a}(1 \mathrm{~s})$. The types of seismic sources associated with specific magnitude and distance combinations are noted on each plot.

resulting in the prediction of less low-frequency content in Seattle, which is about $100 \mathrm{~km}$ away from the Cascadia subduction zone [37]. Although [39] is the most recent hazard model for which national deaggregation data is presently available, the newer [40] was adopted for the calculations here, since it is more refined and based, in part, on data from recent large magnitude subduction earthquakes. Therefore, deaggregation calculations based on the 2014 national seismic hazard model [37], which incorporates [40], are likely to predict lesser separation between the curves in Fig. 7b.

\subsection{Motivation for computing source-specific targets}

To understand the motivation for computing source-specific targets, consider the consequences of computing only one target distribution of $D s_{5-75}$ and conditional spectrum at the hazard level corresponding to the $2 \%$ in 50 year exceedance probability of $S_{a}(1 \mathrm{~s})$ in Seattle, without discriminating between contributing earthquake scenarios based on the type of seismic source, as recommended by Lin et al. [34]. In this case, one conditional median target $D s_{5-75}$ of $10 \mathrm{~s}$, and one conditional mean spectrum would be computed as the average of the source-specific conditional median targets, weighted by their corresponding $\bar{p}_{(s t)}$ values. The standard deviations of these 

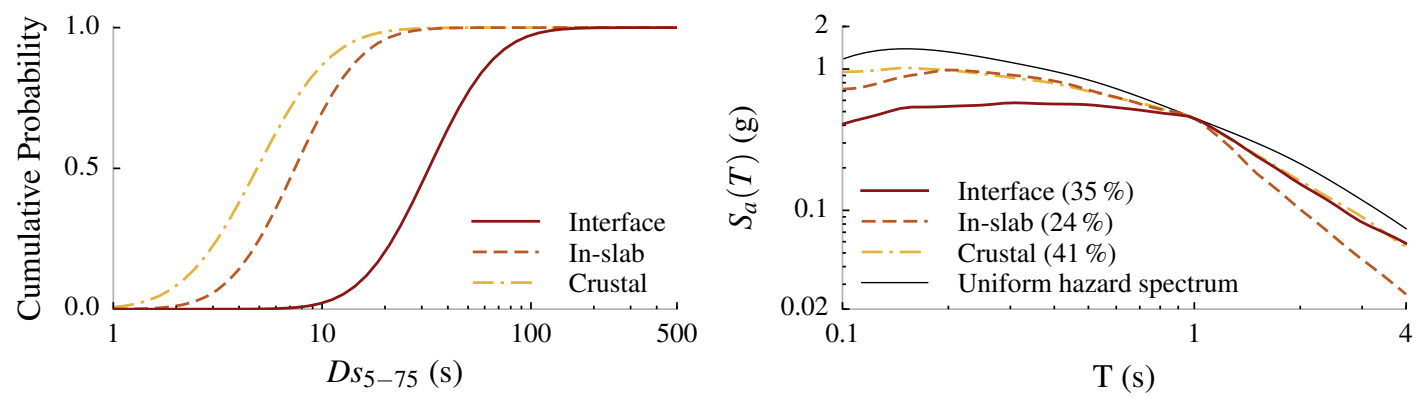

(a) Seattle
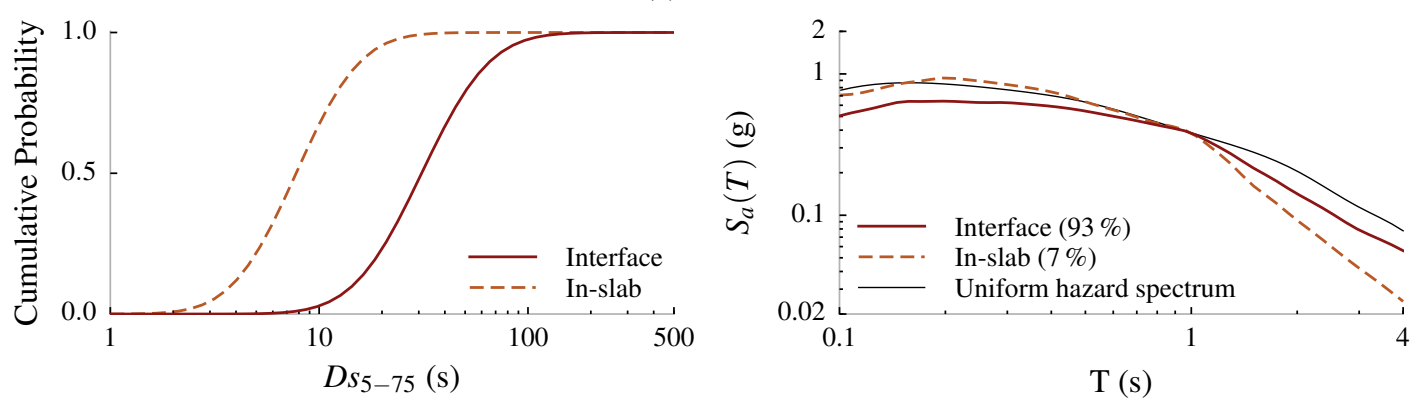

(b) Eugene
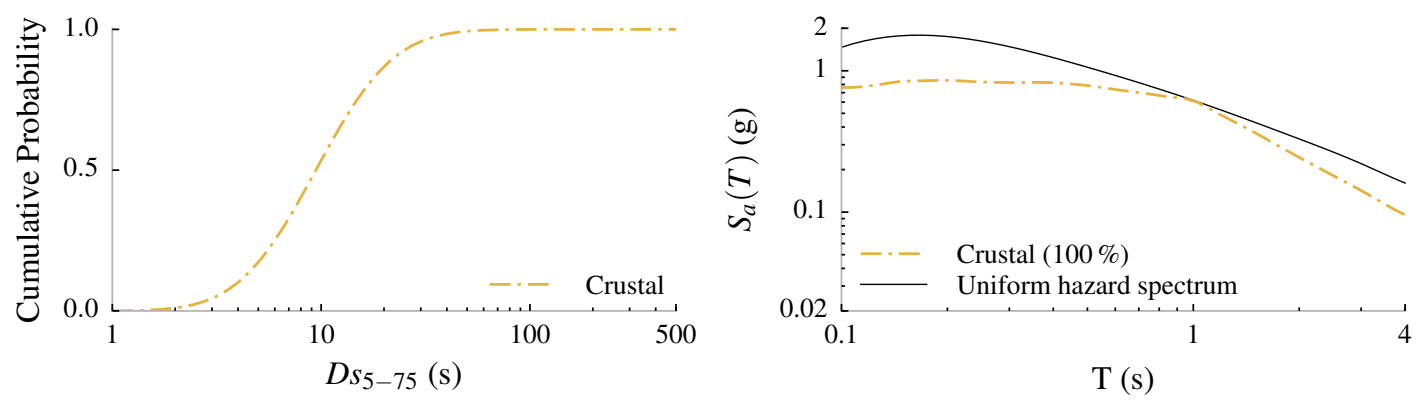

(c) San Francisco

Figure 6. (Left) Source-specific conditional distributions of $D s_{5-75}$, and (Right) source-specific conditional mean spectra and corresponding uniform hazard spectra for all three considered sites, conditional on the $2 \%$ in 50 year exceedance probability of $S_{a}(1 \mathrm{~s})$.

targets would be larger than the standard deviations of the individual source-specific targets, since they would account for the variability $(i)$ among the different types of seismic sources, and $(i i)$ in the characteristics of the ground motions produced by each type of seismic source. Using these targets could lead to the selection of long duration records with a response spectral shape characteristic of shorter duration crustal records, and vice versa, which would not reflect the known differences in the characteristics of ground motions produced by the three types of seismic sources, as observed in Fig. 6. Although this is a concern in a site like Seattle, with hazard contributions from multiple types of sources, it is less of a concern in a site like San Francisco, whose seismic hazard is dominated by one type of source.

Goda and Atkinson [44] address this issue by selecting ground motions to match source-specific conditional mean spectra but they do not consider the spectral standard deviations or ground motion duration. Bradley [35] addresses this issue by recommending the selection of ground motions with characteristics consistent with deaggregated contributing earthquake scenarios, that are simulated from a probability mass function defined by the seismic hazard deaggregation weights. The use, here, of targets averaged over types of seismic sources, although slightly less rigorous than the Bradley procedure, represents a practical middle ground between the recommendations of Lin et 


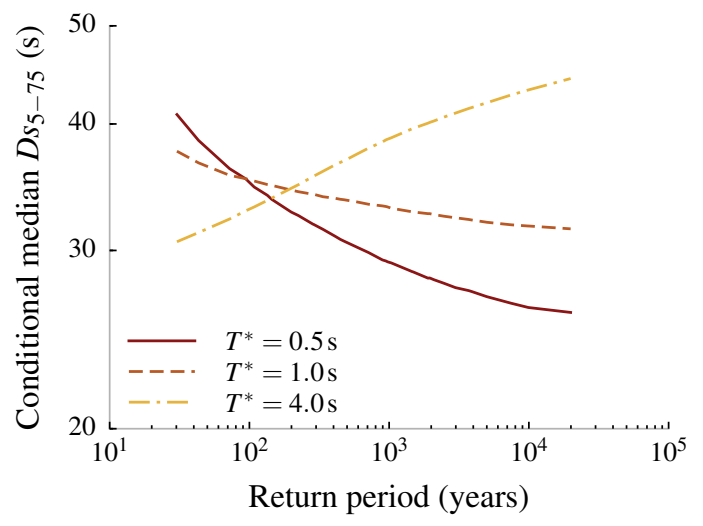

(a)

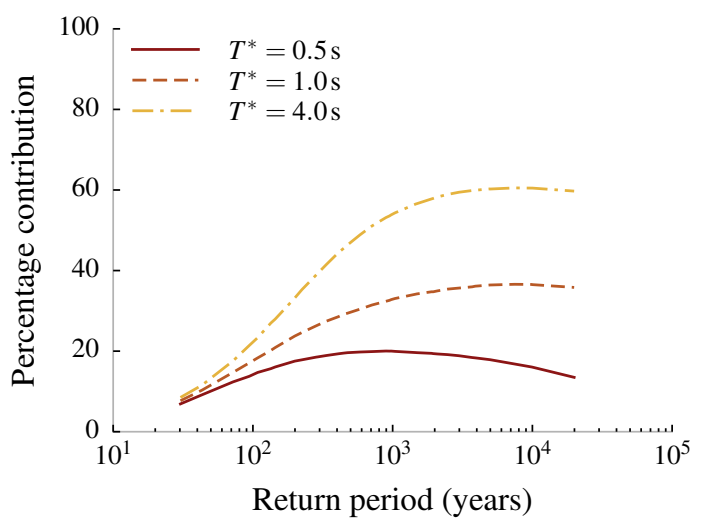

(b)

Figure 7. (a) Conditional median target $D s_{5-75}$ of ground motions in Seattle produced by interface earthquakes, and (b) the percentage contribution to the total seismic hazard of Seattle from interface earthquakes, conditional on different exceedance rates of $S_{a}\left(T^{*}\right)$, i.e. different seismic hazard levels, for different conditioning periods, $T^{*}$.

al. [34] and Bradley [35]. This approach takes advantage of the similarity in the causal parameters that define the contributing earthquake scenarios from each type of source, as observed in Fig. 5. Moreover, the adopted procedure allows the explicit quantification and comparison of the expected duration and frequency content of ground motions produced by interface, in-slab, and crustal earthquakes. It also allows the selection of ground motions representing individual source types to be more finely optimized than the Bradley procedure, as illustrated in the following section.

\section{COLLAPSE RISK ASSESSMENT OF A REINFORCED CONCRETE MOMENT FRAME BUILDING}

\subsection{Structural model}

A ductile eight-story reinforced concrete moment frame building, designed to current standards for a site in Seattle, is used to illustrate the proposed method for characterizing ground motion hazard, and to quantify the influence of ground motion duration on structural collapse risk. The height of the first story of the building is $4.6 \mathrm{~m}$, and the height of all subsequent stories is $4.0 \mathrm{~m}$. The width of each bay of the building is $6.1 \mathrm{~m}$. A schematic of the two-dimensional numerical model of the structure, created and analyzed using OpenSees rev. 5184 [45], is shown in Fig. 8. This model was developed by Raghunandan et al. [46] to study the collapse risk of structures in the Pacific Northwest. The beams and columns of the frame were modeled using linear elastic elements, with zero-length plastic hinges located at the ends of each beam and column. The plastic hinges were modeled using the Modified Ibarra-Medina-Krawinkler peak-oriented model [47] that includes a post-peak negative stiffness branch of the backbone curve to capture in-cycle deterioration, as well as cyclically deteriorating strength and stiffness based on the cumulative hysteretic energy dissipated. Finite panel zones were modeled, with elastic shear deformations. The contribution of the adjacent gravity system to the destabilizing $P-\Delta$ effect was modeled using a pin-connected leaning column. Previous studies have demonstrated that structural models need to capture the deterioration in strength and stiffness of structural components at large inelastic deformations, as well as the destabilizing effect of gravity loads, to capture the effect of ground motion duration on structural response [1,2]. Further details about the design and the numerical model are provided in [46]. 


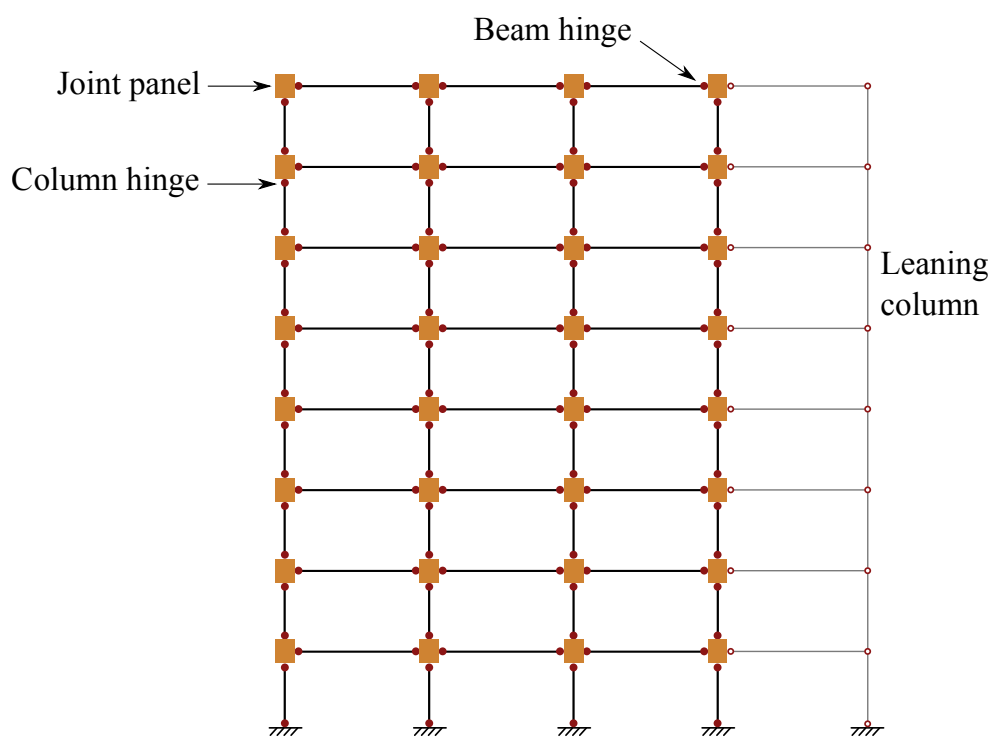

Figure 8 . Schematic of the eight-story reinforced concrete moment frame model.

\subsection{Ground motion selection}

The multiple stripe analysis technique [29], which allows the use of a different set of hazardconsistent ground motions at each intensity level, was used to estimate the collapse fragility curve of the structure. Three groups of ground motions were selected to demonstrate the importance of considering ground motion duration when estimating structural collapse risk. Each group consists of sets of 100 ground motions selected at eight ground motion intensity levels. The ground motions were selected to match targets computed for a site in Seattle, using a conditioning period of $1.8 \mathrm{~s}$, the fundamental period of the structure. Seismic hazard deaggregation results for $S_{a}(1 \mathrm{~s})$ and $S_{a}(2 \mathrm{~s})$, obtained from [38], were interpolated to compute the targets conditional on $S_{a}(1.8 \mathrm{~s})$. The conditional median target $D s_{5-75}$ values and the percentage contribution of interface, in-slab, and crustal earthquakes to the site seismic hazard, at all eight intensity levels, are summarized in the digital appendix, available at http:/ / purl. stanford.edu/nj619hk1456. An upper limit of 5.0 was imposed on the factor used to scale the selected ground motions.

The ground motions in the first group, called the CS and duration group, were selected to match the source-specific target distributions of $D s_{5-75}$ and response spectra, conditional on exceedance of each ground motion intensity level. Ground motions corresponding to interface earthquakes were selected from a collection of 3955 ground motions recorded from the following interface earthquakes: 1974 Lima (Peru), 1985 Valparaiso (Chile), 1985 Michoacan (Mexico), 2003 Hokkaido (Japan), 2010 Maule (Chile), and 2011 Tohoku (Japan). Of these 3955 ground motions, 2448 are from the 2011 Tohoku earthquake, 1314 are from the 2003 Hokkaido earthquake, and the remaining 193 are from the other earthquakes. Ground motions corresponding to both crustal and inslab earthquakes were selected from the PEER NGA-West2 database [36], even though the database contains ground motions only from shallow crustal earthquakes. This was considered reasonable since the magnitudes and target ground motion durations of the contributing in-slab earthquakes were similar to those of the ground motions in the database. Moreover, only a small fraction of ground motions from in-slab earthquakes were required at the high intensity levels, due to their low percentage contribution to the seismic hazard at these intensity levels.

A slightly modified version of the algorithm proposed by Jayaram et al. [17] was used to select ground motions to match a target multivariate normal distribution of logarithms of intensity measures. $D s_{5-75}$ was added as an additional intensity measure to a vector of response spectral ordinates at different periods. The quality of fit of a set of ground motions to the target multivariate distribution was assessed by first computing the Kolmogorov-Smirnov test (K-S test) statistic for 

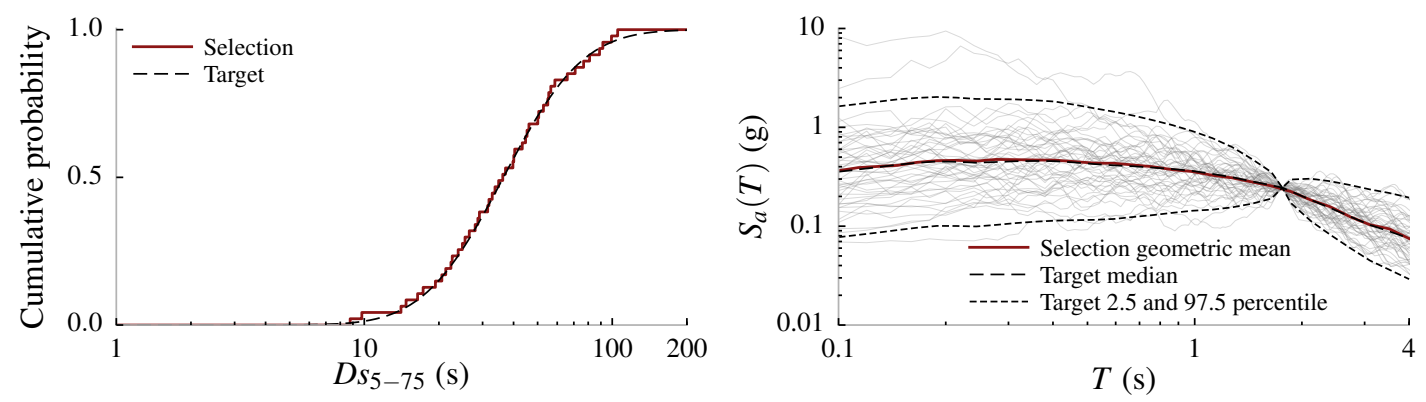

(a) Interface earthquakes: 47 / 100 ground motions
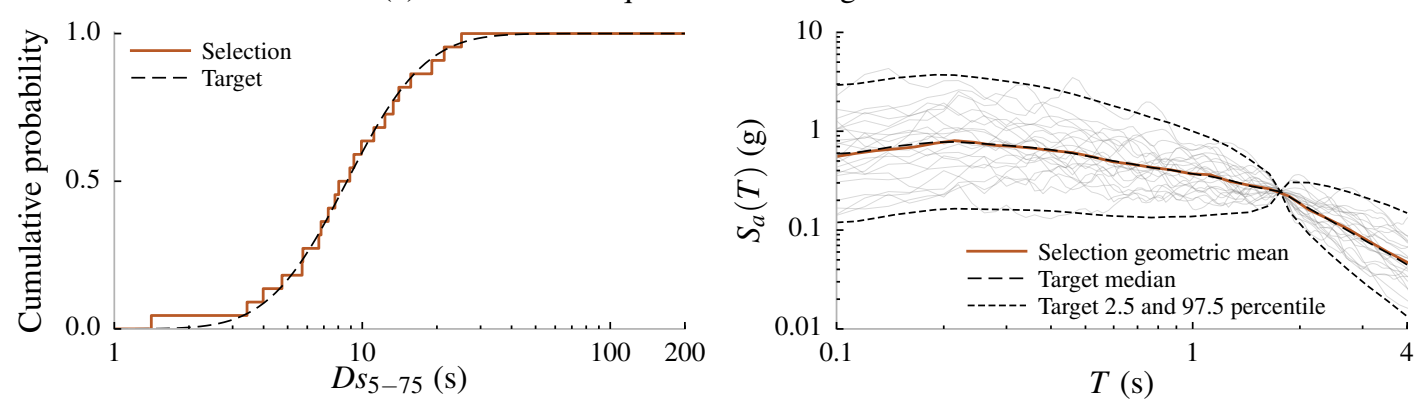

(b) In-slab earthquakes: 22 / 100 ground motions
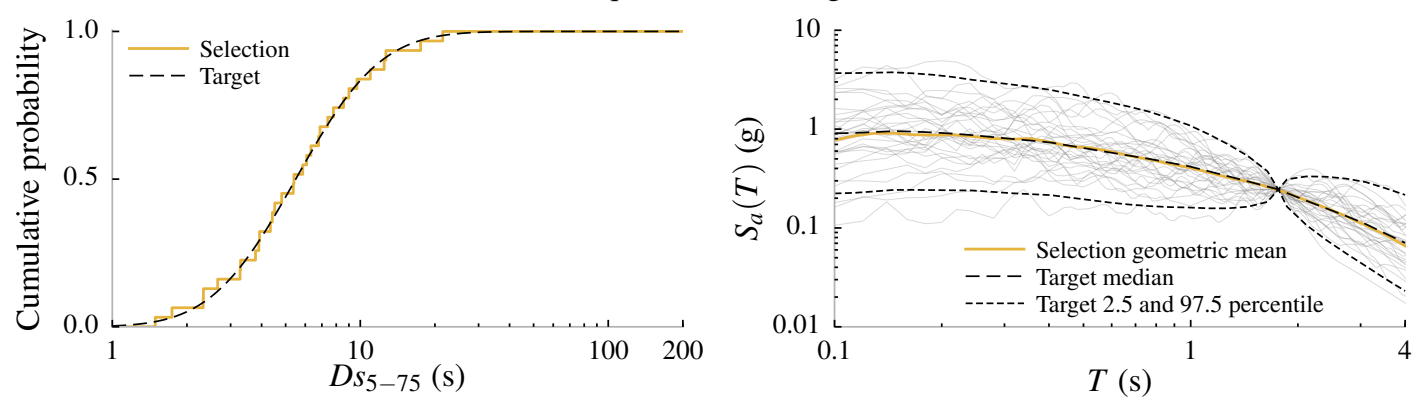

(c) Crustal earthquakes: $31 / 100$ ground motions

Figure 9. Ground motions selected in the $C S$ and duration group at the $S_{a}(1.8 \mathrm{~s})=0.24 \mathrm{~g}$ intensity level

( $2 \%$ in 50 year hazard level) in Seattle, corresponding to each type of contributing seismic source.

each intensity measure, and then computing a weighted average of the test statistics for all intensity measures, similar to the procedure adopted by Bradley [35]. From preliminary trials, weights of 0.5 for the K-S test statistic of $D s_{5-75}$ and 0.5 for the mean K-S test statistic of all response spectral ordinates were found to produce ground motion sets that matched the targets reasonably well. The durations and response spectra of the set of ground motions selected at the $S_{a}(1.8 \mathrm{~s})=0.24 \mathrm{~g}$ intensity level (corresponding to the $2 \%$ in 50 year hazard level) are shown in Fig. 9.

A second group of ground motion sets, called the CS only group, was created to control for the effect of response spectral shape. These ground motions were selected to match only the target distributions of response spectral ordinates, without considering ground motion duration. For this group, ground motions corresponding to all three types of seismic sources were chosen from the PEER NGA-West2 database. The objective of selecting this group was to analyze the consequences of selecting ground motions without explicit consideration of their durations. The durations and response spectra of the ground motions selected to match the targets corresponding to interface earthquakes, at the $S_{a}(1.8 \mathrm{~s})=0.24 \mathrm{~g}$ intensity level, are shown in Fig. 10. As expected, the response spectra of the selected ground motions match the target well, but their durations are shorter than the target. On the other hand, the durations of the ground motions corresponding to crustal and in-slab earthquakes were found to approximately match their targets since the targets 

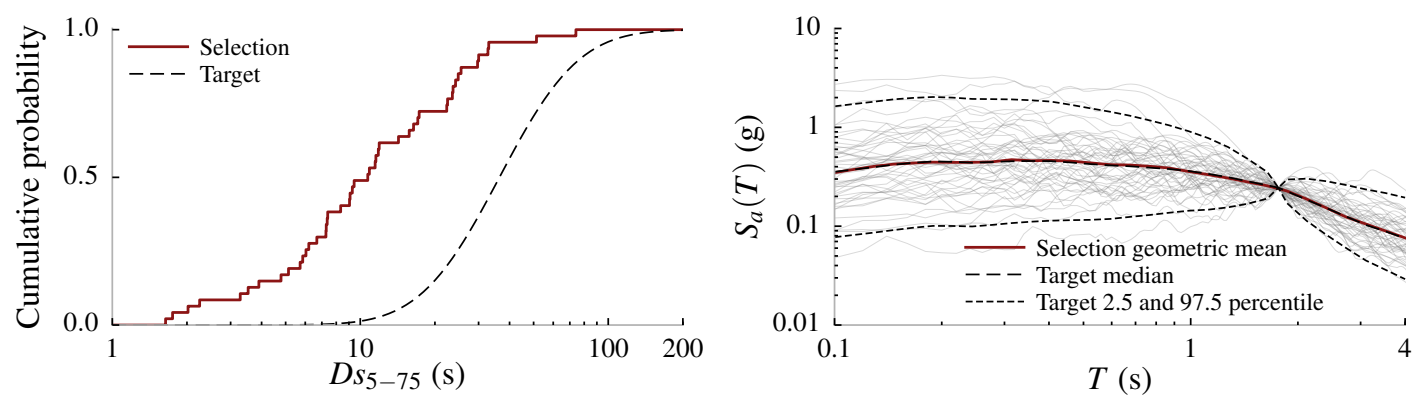

(a) Interface earthquakes: 47 / 100 ground motions

Figure 10. Ground motions selected in the $C S$ only control group at the $S_{a}(1.8 \mathrm{~s})=0.24 \mathrm{~g}$ intensity level ( $2 \%$ in 50 year hazard level) in Seattle, corresponding to interface earthquakes.

Table II. Constraints on the magnitude, $M$, source-to-site distance, $R$, and site $V s_{30}$ of the ground motions selected into the $C S$ and causal parameters group, relative to the target source-specific mean causal magnitude and source-to-site distance obtained from deaggregation results, at the $S_{a}(1.8 \mathrm{~s})=0.24 \mathrm{~g}$ intensity level (2\% in 50 year hazard level) in Seattle.

\begin{tabular}{|c|c|c|c|c|c|c|c|c|c|c|c|}
\hline \multirow{2}{*}{$\begin{array}{l}\text { Seismic } \\
\text { source } \\
\text { type }\end{array}$} & \multicolumn{3}{|c|}{ Target } & \multicolumn{6}{|c|}{ Selection constraints } & \multirow{2}{*}{$\begin{array}{c}\text { No. of } \\
\text { suitable } \\
\text { records }\end{array}$} & \multirow{2}{*}{$\begin{array}{l}\text { No. of } \\
\text { selected } \\
\text { records }\end{array}$} \\
\hline & $\bar{M}$ & $\begin{array}{c}\overline{\boldsymbol{R}} \\
(\mathrm{km})\end{array}$ & $\begin{array}{l}V s_{30} \\
(\mathrm{~m} / \mathrm{s})\end{array}$ & $M_{\min }$ & $M_{\max }$ & $\begin{array}{l}\boldsymbol{R}_{\min } \\
(\mathrm{km})\end{array}$ & $\begin{array}{l}R_{\max } \\
(\mathrm{km})\end{array}$ & $\begin{array}{c}\boldsymbol{V} s_{30, \min } \\
(\mathrm{m} / \mathrm{s})\end{array}$ & $\begin{array}{c}\boldsymbol{V} s_{30, \max } \\
(\mathrm{m} / \mathrm{s})\end{array}$ & & \\
\hline Interface & 8.9 & 114 & 760 & 8.6 & 9.2 & 74 & 154 & - & - & 168 & 47 \\
\hline In-slab & 6.9 & 62 & 760 & 6.4 & 7.4 & 42 & 82 & 360 & 1160 & 48 & 22 \\
\hline Crustal & 6.9 & 7 & 760 & 6.4 & 7.4 & 2 & 12 & 360 & 1160 & 82 & 31 \\
\hline
\end{tabular}

are similar to the durations of the ground motions in the PEER NGA-West2 database. These trends were consistent among all eight ground motion sets in the group. A similar ground motion selection exercise by Chandramohan et al. [1] found that no statistically significant differences are introduced with respect to ground motion characteristics other than response spectra and duration, when comparing the response of a structure to two groups of ground motions recorded from interface and crustal earthquakes respectively. Therefore, any difference observed in the structural collapse risk estimated using the CS and duration and CS only groups can be attributed to the difference in the durations of their ground motions.

Finally, a third group of ground motion sets, called the CS and causal parameters group, was created to evaluate the effectiveness of widely employed ground motion selection procedures that use causal parameters like magnitude, source-to-site distance, and site $V s_{30}$ to implicitly account for the effects of ground motion characteristics like duration, that are not entirely captured by response spectra. The ground motions in this group were also selected to match the target distributions of response spectral ordinates, similar to the other two groups. In addition, only those ground motions recorded from earthquakes whose magnitudes and source-to-site distances lie within an allowable range around the mean magnitude and source-to-site distance of earthquakes from each type of contributing source, obtained from seismic hazard deaggregation results, were considered. Constraints were also placed on the site $V s_{30}$ of the ground motions selected from the PEER NGAWest2 database, assuming the structure is located on a rock site with $V s_{30}=760 \mathrm{~m} / \mathrm{s}$. Since $V s_{30}$ data was not available for many of the interface earthquake ground motions, the $V s_{30}$ constraint was not imposed on them. The specific constraints imposed at the $S_{a}(1.8 \mathrm{~s})=0.24 \mathrm{~g}$ intensity level, corresponding to each type of contributing seismic source, are summarized in Table II. The durations and response spectra of the ground motions corresponding to interface earthquakes, selected at the $S_{a}(1.8 \mathrm{~s})=0.24 \mathrm{~g}$ and $0.49 \mathrm{~g}$ intensity levels (corresponding to the $2 \%$ and $0.25 \%$ in 50 year hazard levels respectively), are shown in Fig. 11.

The response spectra of the interface earthquake ground motions selected at the $S_{a}(1.8 \mathrm{~s})=$ $0.24 \mathrm{~g}$ intensity level are seen to match their targets well, but those selected at the $S_{a}(1.8 \mathrm{~s})=0.49 \mathrm{~g}$ intensity level produce a poorer fit, with larger response spectral ordinates than the targets at periods 

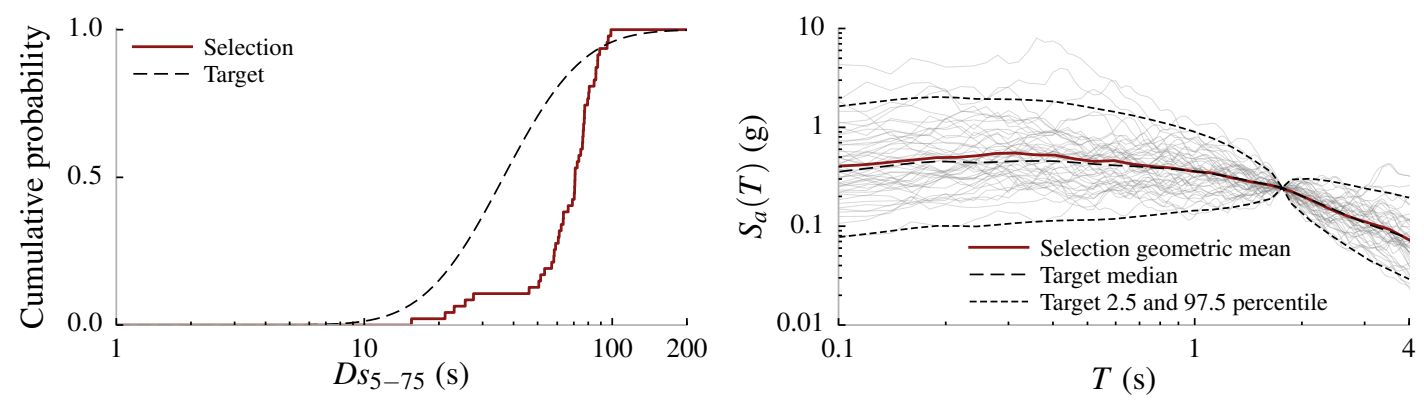

(a) Interface earthquakes: 47 / 100 ground motions
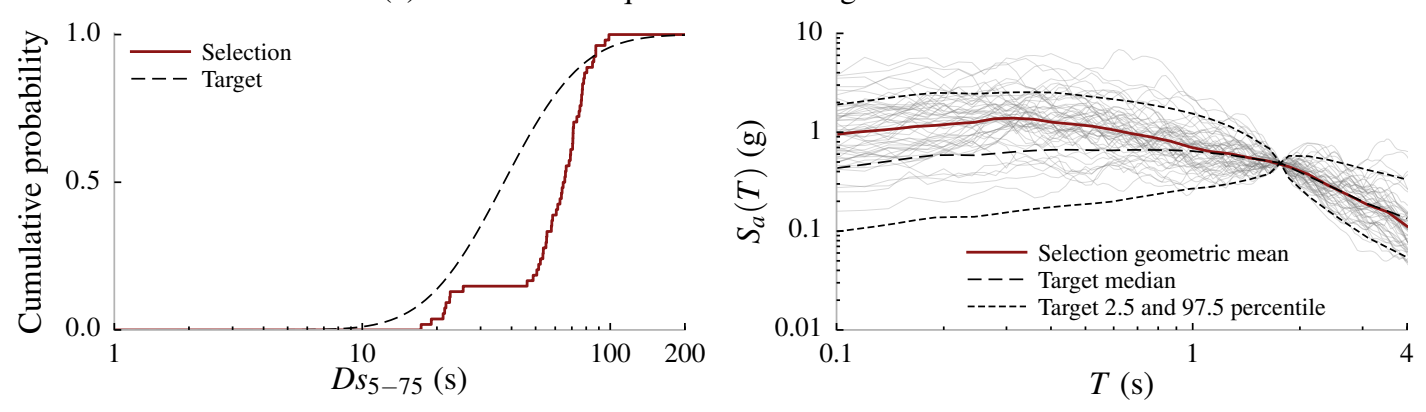

(b) Interface earthquakes: 54 / 100 ground motions

Figure 11. Ground motions selected in the $C S$ and causal parameters group at the (a) $S_{a}(1.8 \mathrm{~s})=0.24 \mathrm{~g}$ intensity level ( $2 \%$ in 50 year hazard level), and the (b) $S_{a}(1.8 \mathrm{~s})=0.49 \mathrm{~g}$ intensity level $(0.25 \%$ in 50 year hazard level) in Seattle, corresponding to interface earthquakes.

below the conditioning period. The response spectra of the ground motions corresponding to crustal and in-slab earthquakes also follow similar trends. These poorer fits are a consequence of the limited number of recorded ground motions that satisfy the constraints imposed on the causal parameters, even though the constraints used here are somewhat relaxed compared to those used in conventional ground motion selection practice. This is evident from the last two columns of Table II, which list the number of ground motions available to select from, and the number of selected ground motions, at the $S_{a}(1.8 \mathrm{~s})=0.24 \mathrm{~g}$ intensity level. Although this problem could be slightly alleviated by increasing the maximum permissible ground motion scale factor, the scaling of low amplitude ground motions by large scale factors can produce other inconsistencies, and is not recommended. The number of available ground motions gets even smaller at higher intensity levels, thus leading to even poorer fits. Therefore, while the selection of ground motions based on causal parameters might work well for evaluations conducted at low intensity levels, it is not as reliable when selecting ground motions at higher intensity levels for collapse risk estimation. This suggests that aggressive screening of candidate ground motions with respect to causal parameters can be counterproductive, since it can result in the selection of ground motions with less desirable response spectra and durations: properties known to more directly influence structural response. Causal parameters like magnitude, source-to-site distance, and site $V s_{30}$, which only implicitly control time series characteristics, should be a secondary consideration to the time series characteristics themselves.

The durations of the selected ground motions corresponding to interface earthquakes are seen to be longer than their target at both intensity levels. This trend is observed at all eight intensity levels, and is an artifact of the limited number of recorded earthquakes with magnitudes within the range of the imposed constraints: in this case, only the 2010 Maule (Chile) and 2011 Tohoku (Japan) earthquakes. The step in the empirical cumulative distributions of $D s_{5-75}$ distinguish the relatively shorter duration records from the 2010 Maule earthquake $\left(D s_{5-75} \sim 20 \mathrm{~s}-30 \mathrm{~s}\right.$ ) from the relatively longer duration records from the 2011 Tohoku earthquake $\left(D s_{5-75} \sim 50 \mathrm{~s}-90 \mathrm{~s}\right.$ ). The durations of the selected ground motions corresponding to crustal and in-slab earthquakes 


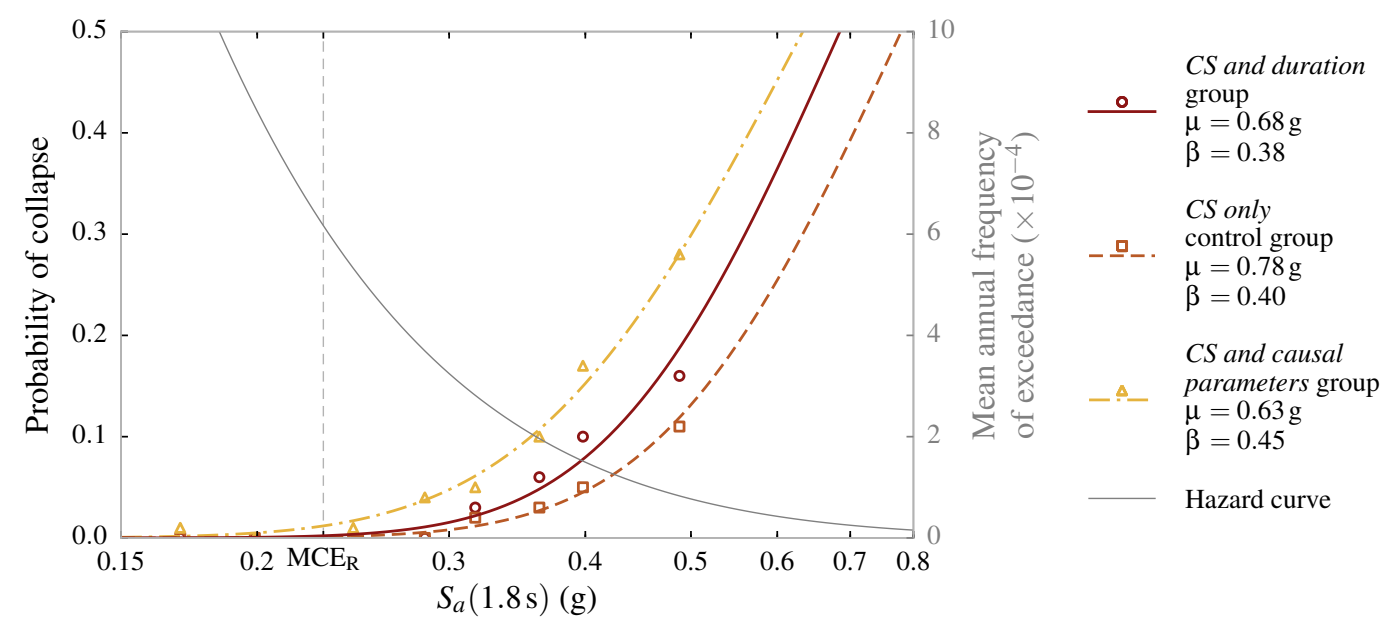

Figure 12. Collapse fragility curves of the reinforced concrete moment frame building, estimated using the three groups of selected ground motions (with median, $\mu$, and lognormal standard deviation, $\beta$, indicated in the legend), along with the seismic hazard curve and the $\mathrm{MCE}_{\mathrm{R}}$ ground motion intensity for Seattle.

do, however, approximately match their targets at all eight intensity levels for same the reasons described above for the CS only control group.

Plots of the durations and response spectra of all the ground motions selected into the three groups (similar to Fig. 9), at all eight intensity levels, are available in the digital appendix. Summaries of the constraints imposed on the magnitude, source-to-site distance, and site $V s_{30}$ of the ground motions selected into the CS and causal parameters group (similar to Table II), at each intensity level, are also included.

\subsection{Collapse risk estimation}

The collapse fragility of the reinforced concrete moment frame building was estimated using each of the three groups of ground motions described in Section 4.2, selected to match the seismic hazard targets computed for Seattle. This entailed analyzing the structure under each ground motion and checking whether it led to structural collapse, which is indicated by the unbounded increase in the drift ratio at a story, above a threshold of 0.10 . The adopted collapse story drift ratio threshold of 0.10 was chosen based on studies which indicated that it provides a fairly consistent measure of when the structure collapses by dynamic instability. Numerical time integration was performed using the explicit central difference scheme, since it was found to be more robust and efficient than implicit time integration schemes, which sometimes failed to converge. The fraction of ground motions that caused structural collapse at each intensity level was plotted against $S_{a}(1.8 \mathrm{~s})$, and a collapse fragility curve was computed by fitting a lognormal cumulative distribution function to the data using maximum likelihood estimation. Note that maximum likelihood estimation requires all ground motions at an intensity level to be independent, but this may not be the case for ground motions recorded from the same earthquake. Nonetheless, this is not expected to significantly influence the obtained results [48]. The resulting collapse fragility curves estimated using the three groups of ground motions are shown in Fig. 12, along with the seismic hazard curve for Seattle.

The first observation from Fig. 12 is that a larger fraction of the ground motions at the four highest intensity levels cause structural collapse in the CS and duration group than the CS only control group. Since the ground motions in these two groups have equivalent response spectra, the larger fraction of collapses can be attributed to the presence of longer duration ground motions corresponding to interface earthquakes in the CS and duration group (compare Figs. 9a and 10). This inference is supported by the fact that at the four highest intensity levels, 3 out of 3,5 out of 6,8 out of 10 , and 10 out of 16 of the ground motions from the CS and duration group that caused structural collapse are from interface earthquakes. These results are consistent with those 
obtained by Raghunandan et al. [46], who also concluded that long duration ground motions from interface earthquakes are more likely to cause the collapse of ductile moment frame buildings in Seattle. A more detailed comparison of the results is, however, not possible since [46] did not employ hazard-consistent ground motions. Although the adopted analysis procedure accounts for the uncertainty in the characteristics of the anticipated ground motions, it ignores the uncertainty in the characteristics of the structural model [12]. This simplification was considered appropriate for this study since it is the relative values of collapse risk estimates that are used to compare ground motion selection procedures; the absolute values are of lesser concern. The mean annual frequency of collapse, $\lambda_{\text {collapse }}$, computed by integrating the product of the collapse fragility curve and the derivative of the seismic hazard curve, is estimated to be $5.4 \times 10^{-5}$ using the CS and duration group, and $3.8 \times 10^{-5}$ using the CS only control group. Therefore, ignoring ground motion duration results in an unconservative underestimation of $\lambda_{\text {collapse }}$ by $29 \%$. Note that if the Kempton and Stewart [24] prediction equation for $D s_{5-75}$ were used instead of Abrahamson and Silva [23], longer duration ground motions would have been selected in the CS and duration group (see Fig. 2), and subsequently, an even larger effect of duration on $\lambda_{\text {collapse }}$ would have been observed.

This estimate of the percentage difference in $\lambda_{\text {collapse }}$, hereby abbreviated as $\Delta \lambda_{\text {collapse }}$, has an associated standard error, which can be estimated by bootstrapping [30]. Here, we extend the method proposed by Eads et al. [49], by enabling the estimation of the standard error in collapse risk estimates obtained using a multiple stripe analysis. Bootstrapping estimates the distribution of a statistic by repeatedly resampling from the observed data with replacement. In this case, a bootstrap estimate of the fraction of ground motions that cause structural collapse at an intensity level was made by sampling 100 ground motions with replacement, from the original 100 ground motions used at that intensity level. A collapse fragility curve was then fit to the resampled fractions of ground motions causing structural collapse at all eight intensity levels, and the corresponding $\lambda_{\text {collapse }}$ was computed.

Ten thousand such bootstrap estimates of the collapse fragility curve corresponding to the CS and duration group were made, a subset of which are plotted in Fig. 13a. The standard error of the value of $\lambda_{\text {collapse }}$ estimated using the $C S$ and duration group was then computed as the sample standard deviation of the ten thousand values of $\lambda_{\text {collapse }}$ computed from the bootstrapped collapse fragility curves. The computed standard error was $0.68 \times 10^{-5}$, which is $13 \%$ of $5.4 \times 10^{-5}$, the estimated value of $\lambda_{\text {collapse }}$. It is evident from Fig. 13a that the collapse fragility curve is well constrained only below the highest intensity level at which analyses were conducted $\left(S_{a}(1.8 \mathrm{~s})=0.49 \mathrm{~g}\right.$ in this case). Large contributions to the structural collapse risk from higher intensity levels would, therefore, cause the standard error of the estimate of $\lambda_{\text {collapse }}$ to increase, thus highlighting the importance of appropriately selecting the ground motion intensity levels at which to analyze the structure. The standard error of any other parameter, like the median or lognormal standard deviation of the collapse fragility curve, could be estimated in a similar manner. Following the same procedure, ten thousand bootstrap estimates of the collapse fragility curve corresponding to the CS only control group were also made, and the corresponding $\lambda_{\text {collapse }}$ values were computed. The ten thousand bootstrap estimates from the two groups were then taken in pairs and used to compute ten thousand values of $\Delta \lambda_{\text {collapse }}$. The histogram of these $\Delta \lambda_{\text {collapse }}$ values, shown in Fig. 13b, describes the empirical sampling distribution of $\Delta \lambda_{\text {collapse }}$, and quantifies the influence of ground motion duration on the collapse risk of the structure located in Seattle. Although the number of bootstrap simulations used is in excess of that required to obtain stable estimates, no effort was made to optimize this number given the ease of producing large numbers of simulations. The standard error of $\Delta \lambda_{\text {collapse }}$ was computed to be $16 \%$. The empirical $p$-value of a hypothesis test [50] with null hypothesis $\Delta \lambda_{\text {collapse }}=0$ was computed as 0.06 : the fraction of all simulated $\Delta \lambda_{\text {collapse }}$ values that are lesser than zero. This is only slightly above the conventionally accepted threshold of 0.05 and indicates that if the effect of duration is considered to be statistically significant by rejecting the null hypothesis, there is a $6 \%$ probability of doing so erroneously, i.e. encountering a Type-1 error. The standard error of $\Delta \lambda_{\text {collapse }}$ can be reduced by analyzing the structure using more ground motions at each intensity level. 


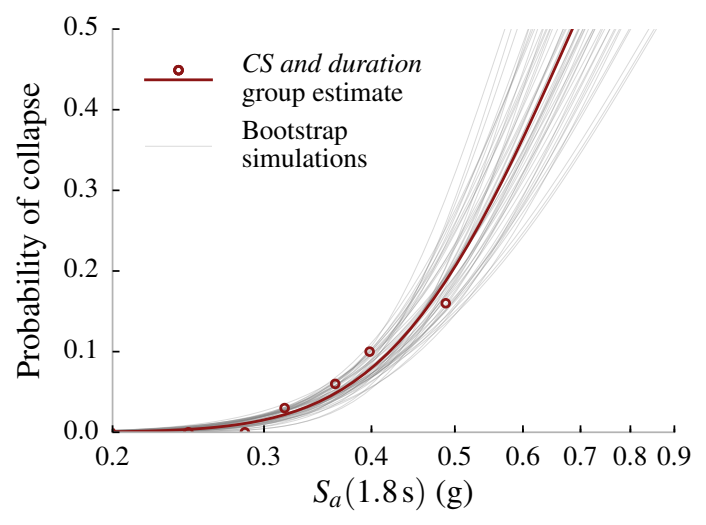

(a)

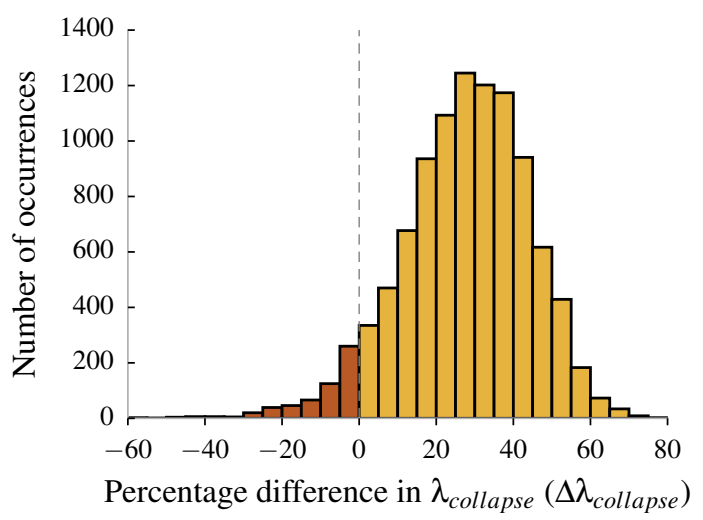

(b)

Figure 13. (a) Bootstrap estimates of the collapse fragility curve corresponding to the CS and duration group, and (b) the histogram of bootstrap estimates of the percentage difference in $\lambda_{\text {collapse }}$ estimated by the $C S$ and duration and $C S$ only ground motion groups $\left(\Delta \lambda_{\text {collapse }}\right)$.

It can also be observed from Fig. 12 that the fraction of ground motions from the CS and causal parameters group that cause structural collapse at each intensity level is even larger than the $C S$ and duration group. This overestimation of the collapse risk can be attributed to $(i)$ the longer durations of the ground motions in the CS and causal parameters group selected to match targets corresponding to interface earthquakes (with median $D s_{5-75}$ almost twice the conditional median targets at all intensity levels), and (ii) the larger response spectral ordinates at periods below the conditioning period, of the ground motions selected to match targets corresponding to all types of sources at high intensity levels (e.g. compare Figs. 9a and 11, or refer to similar plots in the digital appendix). Of the two factors, the effect of longer duration ground motions is expected to be more dominant, since the collapse response of the structure is expected to be controlled primarily by spectral ordinates at periods above the conditioning period. The $\lambda_{\text {collapse }}$ estimated by the $C S$ and causal parameters group is $53 \%$ larger than the value estimated using the CS and duration group. The standard error of this $\Delta \lambda_{\text {collapse }}$ value is $25 \%$, and the empirical $p$-value is 0.00 , which implies that the estimated value of $\Delta \lambda_{\text {collapse }}$ is statistically significant. This bias in the estimated collapse risk provides further evidence of the drawbacks of relying too much on earthquake causal parameters to capture effects that are better represented by duration and response spectra.

To contrast the influence of ground motion duration on structural collapse risk for sites in Eugene and San Francisco, the ground motion selection and collapse risk assessment procedure described above, was repeated for these two sites. The durations and response spectra of the ground motions selected into the three groups for Eugene and San Francisco were found to follow identical trends as those selected for Seattle, when compared to their respective targets. The same building was used at all sites, although it was designed for a site in Seattle, to simplify the comparison of different ground motion selection procedures. Plots of the durations and response spectra of all the selected ground motions are available in the digital appendix, along with the collapse fragility curves estimated using them. The $\lambda_{\text {collapse }}$ values estimated using the three groups of ground motions selected for Seattle, Eugene, and San Francisco, are summarized in Table III. In Eugene, the $\lambda_{\text {collapse }}$ estimated by the CS only control group is $59 \%$ lower than that estimated by the CS and duration group. This decrease is larger than the $29 \%$ decrease observed in Seattle and can be explained by the larger percentage contribution from interface earthquakes to the seismic hazard at Eugene, hence resulting in a difference in the durations of a larger fraction of ground motions in the two groups, at each intensity level. In San Francisco, the $\lambda_{\text {collapse }}$ estimated by the CS only control group is only $7 \%$ lower. This small $\Delta \lambda_{\text {collapse }}$ value is the consequence of a near $100 \%$ contribution from crustal earthquakes to the seismic hazard at San Francisco, hence resulting in the selection of ground motions of almost similar duration in both groups. The $\lambda_{\text {collapse }}$ estimated by the CS and causal parameters group is greater than the $\lambda_{\text {collapse }}$ estimated by the CS and duration and CS only groups 
Table III. Mean annual frequency of collapse $\left(\lambda_{\text {collapse }}\right)$ of the reinforced concrete moment frame building, as estimated using the three groups of ground motions selected for the three considered sites. The percentage by which the $\lambda_{\text {collapse }}$ values estimated using the $C S$ only control group and the CS and causal parameters group differ from the value estimated using the $C S$ and duration group is indicated in parentheses.

\begin{tabular}{llll}
\hline Ground motion group & Seattle & Eugene & San Francisco \\
\hline CS and duration group & $5.4 \times 10^{-5}$ & $7.2 \times 10^{-5}$ & $15 \times 10^{-5}$ \\
CS only control group & $3.8 \times 10^{-5}(-29 \%)$ & $2.9 \times 10^{-5}(-59 \%)$ & $14 \times 10^{-5}(-7 \%)$ \\
CS and causal parameters group & $8.2 \times 10^{-5}(+53 \%)$ & $9.7 \times 10^{-5}(+34 \%)$ & $23 \times 10^{-5}(+51 \%)$ \\
\hline
\end{tabular}

in both Eugene and San Francisco, following the same trend observed for Seattle. In the case of Eugene, this can be attributed to the longer durations of the ground motions selected to match targets corresponding to interface earthquakes, as well as the larger response spectral ordinates at periods below the conditioning period, of all the ground motions selected at high intensity levels, similar to the reasons outlined for Seattle above. In the case of San Francisco, however, this can be attributed only to the larger response spectral ordinates, since the durations of ground motions in the CS and causal parameters group are similar to those in the other two groups.

Finally, the lognormal collapse fragility curves estimated using the three groups of ground motions, selected for each of the three sites, were modified to incorporate model uncertainty in an approximate manner, as per the recommendations of FEMA P695 [12]. They were recomputed using the same median, but by adding a lognormal standard deviation of 0.35 , corresponding to modeling uncertainty (as recommended by [12]), using the square root of sum of squares method. Although this change increased the computed $\lambda_{\text {collapse }}$ values as expected, the relative trends between the different ground motion groups and sites were found to remain the same. These trends are expected to be present even if an explicit simulation-based method were used to account for model uncertainty.

\section{CONCLUSION}

A procedure to compute source-specific probability distributions of ground motion duration, conditional on the exceedance of a spectral acceleration value, $S_{a}\left(T^{*}\right)$, was developed. This calculation procedure is based on the generalized conditional intensity measure (GCIM) approach [21]. These source-specific conditional distributions of duration, along with conditional spectra, serve as targets for the selection of hazard-consistent ground motions for structural performance assessment. They were used in this study to assess the impact of considering hazard-consistent duration targets when selecting ground motions for structural collapse risk assessment.

The contribution of long duration ground motions produced by large magnitude interface earthquakes in the Cascadia subduction zone, to the seismic hazard in Western USA was studied. Target distributions of duration and response spectra were computed for sites in Seattle, Eugene, and San Francisco, each of which are located in distinct tectonic settings. While interface, in-slab, and crustal earthquakes contribute to the seismic hazard at Seattle, only interface and in-slab earthquakes contribute to the hazard at Eugene, and only crustal earthquakes contribute to the hazard at San Francisco. Considerations for selecting an appropriate mix of hazard-consistent ground motions for a given seismic hazard environment were discussed, using Seattle as an example.

The impact of explicitly considering ground motion duration targets when selecting records for structural collapse risk assessment was demonstrated by analyzing a ductile eight-story reinforced concrete moment frame building, designed for a site in Seattle. The mean annual frequency of collapse, $\lambda_{\text {collapse }}$, of the structure was first estimated by conducting a multiple stripe analysis using hazard-consistent ground motions, selected to match both duration and response spectrum targets computed for Seattle. When analyzed using standard duration ground motions from the PEER NGA-West 2 database, selected to match only response spectrum targets, $\lambda_{\text {collapse }}$ was found to be underestimated by $29 \%$. This difference was attributed to the difference in the durations of the ground motions in the two groups. Similarly, $\lambda_{\text {collapse }}$ was underestimated by $59 \%$ and $7 \%$ 
when the same structure was analyzed using ground motions selected to match targets computed for Eugene and San Francisco respectively. As expected, ground motion duration was found to be a more important consideration in sites with large contributions to their seismic hazard from large magnitude interface earthquakes. These collapse risk estimates were obtained using the Abrahamson and Silva [23] prediction equation for $D s_{5-75}$. A larger effect of duration would have been observed if the Kempton and Stewart [24] prediction equation were used instead, since it predicts longer ground motion durations. These results are specific to the eight-story moment frame building studied here, and the effect of duration on structural collapse risk may vary depending on structural characteristics like period, ductility, and rate of strength and stiffness deterioration [1].

The bootstrap was proposed as a convenient tool to estimate the sampling distribution and standard error of structural collapse risk parameters estimated using multiple stripe analysis. It was used here to estimate the standard error of the difference in the mean annual frequency of collapse computed using two groups of ground motions.

Commonly used ground motion selection procedures that employ earthquake causal parameters like magnitude, source-to-site distance, and site $V s_{30}$ as surrogates for ground motion characteristics like duration, were found to produce poorer fits to the duration and response spectrum targets due to the limited number of recorded ground motions that satisfy the imposed constraints on the ranges of the causal parameters. As a consequence, ground motions selected using this method to match targets computed for Seattle, were found to overestimate $\lambda_{\text {collapse }}$ by $53 \%$.

The results of this study demonstrate and quantify the potential contribution of ground motion duration to the collapse risk of structures located at sites where large magnitude earthquakes contribute significantly to the seismic hazard. This warrants an explicit consideration of ground motion duration, in addition to response spectra, in the design and assessment of structures located near active subduction zones, which typically produce such large magnitude earthquakes $\left(M_{W} \sim 9.0\right)$. It should be noted, however, that although duration can have a significant influence on structural collapse, its effect on structural response at lower ground motion intensity levels that do not produce deformations large enough to cause significant strength and stiffness deterioration is much less pronounced [51]. Therefore, code-based nonlinear structural assessments conducted at or below the $\mathrm{MCE}_{\mathrm{R}}$ ground motion intensity level are unlikely to detect the influence of duration [1]. This suggests that methods to incorporate the effect of ground motion duration in code-based design procedures should be assessed and calibrated using collapse risk analyses, and then factored into design criteria that are typically evaluated at the $\mathrm{MCE}_{\mathrm{R}}$ intensity level.

\section{ACKNOWLEDGEMENTS}

This work was supported by the State of California through the Transportation Systems Research Program of the Pacific Earthquake Engineering Research Center (PEER) and by Stanford University. Any opinions, findings, conclusions, and recommendations expressed in this material are those of the authors, and do not necessarily reflect those of the funding agencies. The authors thank Meera Raghunandan and Abbie Liel for sharing the numerical model of the moment frame building that was used in this study, and Jeff Bayless and Christine Goulet for sharing scripts used to process the ground motions. The Instituto Geofisico del Peru, Departamento de Geofisica, Universidad de Chile, Comite de la Base Nacional de Datos de Sismos Fuertes, Mexico, and the National Research Institute for Earth Science and Disaster Prevention (NIED), Japan provided ground motions used in this study.

\section{REFERENCES}

1. Chandramohan R, Baker JW, Deierlein GG. Quantifying the influence of ground motion duration on structural collapse capacity using spectrally equivalent records. Earthquake Spectra (in press); doi:10.1193/ 122813EQS298MR2.

2. Raghunandan M, Liel AB. Effect of ground motion duration on earthquake-induced structural collapse. Structural Safety 2013; 41:119-133, doi:10.1016/j.strusafe.2012.12.002.

3. Bommer JJ, Magenes G, Hancock J, Penazzo P. The Influence of Strong-Motion Duration on the Seismic Response of Masonry Structures. Bulletin of Earthquake Engineering 2004; 2(1):1-26, doi:10.1023/B:BEEE.0000038948. 95616.bf.

4. Hancock J, Bommer JJ. A State-of-Knowledge Review of the Influence of Strong-Motion Duration on Structural Damage. Earthquake Spectra 2006; 22(3):827-845, doi:10.1193/1.2220576. 
5. Iervolino I, Manfredi G, Cosenza E. Ground motion duration effects on nonlinear seismic response. Earthquake Engineering \& Structural Dynamics 2006; 35(1):21-38, doi:10.1002/eqe.529.

6. Hancock J, Bommer JJ. Using spectral matched records to explore the influence of strong-motion duration on inelastic structural response. Soil Dynamics and Earthquake Engineering 2007; 27(4):291-299, doi:10.1016/j. soildyn.2006.09.004.

7. Bommer JJ, Scott SG, Sarma SK. Hazard-consistent earthquake scenarios. Soil Dynamics and Earthquake Engineering 2000; 19(4):219-231, doi:10.1016/S0267-7261(00)00012-9.

8. Bommer JJ, Acevedo AB. The Use of Real Earthquake Accelerograms as Input to Dynamic Analysis. Journal of Earthquake Engineering 2004; 8(1):43-91, doi:10.1142/S1363246904001596.

9. Katsanos EI, Sextos AG, Manolis GD. Selection of earthquake ground motion records: A state-of-the-art review from a structural engineering perspective. Soil Dynamics and Earthquake Engineering 2010; 30(4):157-169, doi: 10.1016/j.soildyn.2009.10.005.

10. Shome N, Cornell CA, Bazzurro P, Carballo JE. Earthquakes, Records, and Nonlinear Responses. Earthquake Spectra 1998; 14(3):469-500, doi:10.1193/1.1586011.

11. Baker JW, Cornell CA. Vector-Valued Ground Motion Intensity Measures for Probabilistic Seismic Demand Analysis. Technical Report PEER 2006/08, Pacific Earthquake Engineering Research Center, Berkeley, CA 2006.

12. FEMA. Quantification of Building Seismic Performance Factors. Technical Report FEMA P695, Federal Emergency Management Agency, Washington, D.C. 2009.

13. NIST. Selecting and Scaling Earthquake Ground Motions for Performing Response-History Analyses. Technical Report NIST GCR 11-917-15, National Institute of Standards and Technology, Gaithersburg, MD 2011.

14. ASCE. Minimum Design Loads for Buildings and Other Structures. Technical Report ASCE/SEI 7-16, American Society of Civil Engineers, Reston, VA (in press).

15. PEER TBI. Guidelines for Performance-Based Seismic Design of Tall Buildings. Technical Report PEER 2010/05, Pacific Earthquake Engineering Research Center, Berkeley, CA 2010.

16. Baker JW. Conditional Mean Spectrum: Tool for Ground-Motion Selection. Journal of Structural Engineering 2011; 137(3):322-331, doi:10.1061/(ASCE)ST.1943-541X.0000215.

17. Jayaram N, Lin T, Baker JW. A Computationally efficient ground-motion selection algorithm for matching a target response spectrum mean and variance. Earthquake Spectra 2011; 27(3):797-815, doi:10.1193/1.3608002.

18. Buratti N, Stafford PJ, Bommer JJ. Earthquake Accelerogram Selection and Scaling Procedures for Estimating the Distribution of Drift Response. Journal of Structural Engineering 2011; 137(3):345-357, doi:10.1061/(ASCE)ST. 1943-541X.0000217.

19. Iervolino I, Giorgio M, Galasso C, Manfredi G. Conditional Hazard Maps for Secondary Intensity Measures. Bulletin of the Seismological Society of America 2010; 100(6):3312-3319, doi:10.1785/0120090383.

20. Cosenza E, Manfredi G. The improvement of the seismic-resistant design for existing and new structures using damage criteria. Seismic Design Methodologies for the Next Generation of Codes, Krawinkler H, Fajfar P (eds.), Balkema, Rotterdam, 1997; 119-130.

21. Bradley BA. A generalized conditional intensity measure approach and holistic ground-motion selection. Earthquake Engineering \& Structural Dynamics 2010; 39(12):1321-1342, doi:10.1002/eqe.995.

22. McGuire RK. Probabilistic seismic hazard analysis and design earthquakes: Closing the loop. Bulletin of the Seismological Society of America 1995; 85(5):1275-1284.

23. Abrahamson NA, Silva WJ. Empirical Ground Motion Models. Technical Report, Report to Brookhaven National Laboratory, Upton, NY 1996.

24. Kempton JJ, Stewart JP. Prediction Equations for Significant Duration of Earthquake Ground Motions Considering Site and Near-Source Effects. Earthquake Spectra 2006; 22(4):985-1013, doi:10.1193/1.2358175.

25. Bommer JJ, Stafford PJ, Alarcón JE. Empirical Equations for the Prediction of the Significant, Bracketed, and Uniform Duration of Earthquake Ground Motion. Bulletin of the Seismological Society of America 2009; 99(6):3217-3233, doi:10.1785/0120080298.

26. Bradley BA. Correlation of Significant Duration with Amplitude and Cumulative Intensity Measures and Its Use in Ground Motion Selection. Journal of Earthquake Engineering 2011; 15(6):809-832, doi:10.1080/13632469.2011. 557140 .

27. Abrahamson NA, Al Atik L. Scenario Spectra for Design Ground Motions and Risk Calculation. 9th US National and 10th Canadian Conference on Earthquake Engineering, Toronto, Canada, 2010.

28. Lin T, Haselton CB, Baker JW. Conditional spectrum-based ground motion selection. Part I: Hazard consistency for risk-based assessments. Earthquake Engineering \& Structural Dynamics 2013; 42(12):1847-1865, doi:10.1002/ eqe.2301.

29. Jalayer F. Direct probabilistic seismic analysis: Implementing non-linear dynamic assessments. PhD Thesis, Stanford University 2003.

30. Efron B, Tibshirani RJ. An Introduction to the Bootstrap. CRC Press: Boca Raton, FL, 1994.

31. Kramer SL. Geotechnical earthquake engineering. Prentice-Hall Series in Civil Engineering and Engineering Mechanics, Prentice Hall: Upper Saddle River, NJ, 1996.

32. McGuire RK. Seismic hazard and risk analysis. Earthquake Engineering Research Institute: Oakland, CA, 2004.

33. Trifunac MD, Brady AG. A study on the duration of strong earthquake ground motion. Bulletin of the Seismological Society of America 1975; 65(3):581-626.

34. Lin T, Harmsen SC, Baker JW, Luco N. Conditional Spectrum Computation Incorporating Multiple Causal Earthquakes and Ground-Motion Prediction Models. Bulletin of the Seismological Society of America 2013; 103(2A): 1103-1116, doi:10.1785/0120110293.

35. Bradley BA. A ground motion selection algorithm based on the generalized conditional intensity measure approach. Soil Dynamics and Earthquake Engineering 2012; 40:48-61, doi:10.1016/j.soildyn.2012.04.007.

36. Ancheta TD, Darragh RB, Stewart JP, Seyhan E, Silva WJ, Chiou BSJ, Wooddell KE, Graves RW, Kottke AR, Boore DM, et al.. PEER NGA-West2 Database. Technical Report PEER 2013/03, Pacific Earthquake Engineering Research Center, Berkeley, CA 2013. 
37. Petersen MD, Moschetti MP, Powers PM, Mueller CS, Haller KM, Frankel AD, Zeng Y, Rezaeian S, Harmsen SC, Boyd OS, et al.. Documentation for the 2014 Update of the United States National Seismic Hazard Maps. Technical Report Open-File Report 2014-1091, United States Geological Survey, Reston, VA 2014, doi:10.3133/ofr20141091.

38. USGS. Interactive Deaggregations 2008. URL http://geohazards.usgs.gov/deaggint/2008/.

39. Petersen MD, Frankel AD, Harmsen SC, Mueller CS, Haller KM, Wheeler RL, Wesson RL, Zeng Y, Boyd OS, Perkins DM, et al. Documentation for the 2008 Update of the United States National Seismic Hazard Maps. Technical Report Open-File Report 2008-1128, United States Geological Survey, Reston, VA 2008.

40. Abrahamson NA, Gregor N, Addo K. BC Hydro Ground Motion Prediction Equations For Subduction Earthquakes. Earthquake Spectra (in press); doi:10.1193/051712EQS188MR.

41. Campbell KW, Bozorgnia Y. NGA-West2 Ground Motion Model for the Average Horizontal Components of PGA, PGV, and 5\% Damped Linear Acceleration Response Spectra. Earthquake Spectra 2014; 30(3):1087-1115, doi: 10.1193/062913EQS175M.

42. Baker JW, Jayaram N. Correlation of Spectral Acceleration Values from NGA Ground Motion Models. Earthquake Spectra 2008; 24(1):299-317, doi:10.1193/1.2857544.

43. Al Atik L. Correlation of Spectral Acceleration Values for Subduction and Crustal Models. COSMOS Technical Session, Emeryville, CA, 2011.

44. Goda K, Atkinson GM. Seismic performance of wood-frame houses in south-western British Columbia. Earthquake Engineering \& Structural Dynamics 2011; 40(8):903-924, doi:10.1002/eqe.1068.

45. McKenna F, Fenves GL, Scott MH. OpenSees: Open system for earthquake engineering simulation 2006. URL http: //opensees berkeley. edu.

46. Raghunandan M, Liel AB, Luco N. Collapse Risk of Buildings in the Pacific Northwest Region due to Subduction Earthquakes. Earthquake Spectra 2015; 31(4):2087-2115, doi:10.1193/012114EQS011M.

47. Ibarra LF, Medina RA, Krawinkler H. Hysteretic models that incorporate strength and stiffness deterioration. Earthquake Engineering \& Structural Dynamics 2005; 34(12):1489-1511, doi:10.1002/eqe.495.

48. Baker JW. Efficient Analytical Fragility Function Fitting Using Dynamic Structural Analysis. Earthquake Spectra 2015; 31(1):579-599, doi:10.1193/021113EQS025M.

49. Eads L, Miranda E, Krawinkler H, Lignos DG. An efficient method for estimating the collapse risk of structures in seismic regions. Earthquake Engineering \& Structural Dynamics 2013; 42(1):25-41, doi:10.1002/eqe.2191.

50. Rice JA. Mathematical Statistics and Data Analysis. Cengage Learning: Boston, MA, 2006.

51. Bommer JJ, Crowley H, Pinho R. A risk-mitigation approach to the management of induced seismicity. Journal of Seismology 2015; 19(2):623-646, doi:10.1007/s10950-015-9478-z. 